\title{
Wind turbine drivetrains: state-of-the-art technologies and future development trends
}

\author{
Amir R. Nejad ${ }^{1}$, Jonathan Keller ${ }^{2}$, Yi Guo ${ }^{2}$, Shawn Sheng ${ }^{2}$, Henk Polinder ${ }^{3}$, Simon Watson ${ }^{3}$, \\ Jianning Dong ${ }^{3}$, Zian Qin ${ }^{3}$, Amir Ebrahimi ${ }^{4}$, Ralf Schelenz ${ }^{5}$, Francisco Gutiérrez Guzmán ${ }^{6}$, \\ Daniel Cornel $^{6}$, Reza Golafshan ${ }^{6}$, Georg Jacobs ${ }^{6}$, Bart Blockmans ${ }^{7,8}$, Jelle Bosmans ${ }^{7,8}$, Bert Pluymers ${ }^{7,8}$, \\ James Carroll $^{9}$, Sofia Koukoura ${ }^{9}$, Edward Hart ${ }^{9}$, Alasdair McDonald ${ }^{10}$, Anand Natarajan ${ }^{11}$, \\ Jone Torsvik $^{12}$, Farid K. Moghadam ${ }^{1}$, Pieter-Jan Daems ${ }^{13}$, Timothy Verstraeten ${ }^{13}$, Cédric Peeters ${ }^{13}$, and \\ Jan Helsen ${ }^{13}$ \\ ${ }^{1}$ Marine Technology Department, Norwegian University of Science and Technology, 7491 Trondheim, Norway \\ ${ }^{2}$ National Renewable Energy Laboratory, Golden, CO 80401, USA \\ ${ }^{3}$ Technische Universiteit Delft, Mekelweg 2, 2628 CD Delft, the Netherlands \\ ${ }^{4}$ Institute for Drive Systems and Power Electronics, Leibniz University Hannover, \\ Postfach 6009, 30060 Hannover, Germany \\ ${ }^{5}$ Center for Wind Power Drives (CWD), RWTH Aachen University, Campus-Boulevard 61, \\ 52074 Aachen, Germany \\ ${ }^{6}$ Institute for Machine Elements and Systems Engineering (MSE), RWTH Aachen University, \\ Schinkelstrasse 10, 52062 Aachen, Germany \\ ${ }^{7}$ LMSD Division, Mechanical Engineering Department, KU Leuven, Heverlee, Belgium \\ ${ }^{8}$ Core Lab Dynamics of Mechanical and Mechatronic Systems, Flanders Make, Heverlee, Belgium \\ ${ }^{9}$ Wind Energy and Control Centre, Electronic And Electrical Engineering, University of Strathclyde, 16 \\ Richmond St, Glasgow G1 1XQ, United Kingdom \\ ${ }^{10}$ Institute for Energy Systems, School of Engineering, University of Edinburgh, Edinburgh, United Kingdom \\ ${ }^{11}$ DTU Wind Energy, Frederiksborgvej 399, 4000 Roskilde, Denmark \\ ${ }^{12}$ Equinor ASA, Sandslivegen 90, 5254 Sandsli, Norway \\ ${ }^{13}$ Department of Mechanical Engineering, Vrije Universiteit Brussel, OWI-Lab, B-1050 Brussels, Belgium
}

Correspondence: Amir R. Nejad (amir.nejad@ntnu.no)

Received: 21 June 2021 - Discussion started: 24 June 2021

Revised: 1 October 2021 - Accepted: 29 December 2021 - Published: 21 February 2022

\begin{abstract}
This paper presents the state-of-the-art technologies and development trends of wind turbine drivetrains - the system that converts kinetic energy of the wind to electrical energy - in different stages of their life cycle: design, manufacturing, installation, operation, lifetime extension, decommissioning and recycling. Offshore development and digitalization are also a focal point in this study. Drivetrain in this context includes the whole power conversion system: main bearing, shafts, gearbox, generator and power converter. The main aim of this article is to review the drivetrain technology development as well as to identify future challenges and research gaps. The main challenges in drivetrain research identified in this paper include drivetrain dynamic responses in large or floating turbines, aerodynamic and farm control effects, use of rare-earth material in generators, improving reliability through prognostics, and use of advances in digitalization. These challenges illustrate the multidisciplinary aspect of wind turbine drivetrains, which emphasizes the need for more interdisciplinary research and collaboration.
\end{abstract}




\section{Introduction}

The European Green Deal aims to make the European Union climate-neutral by 2050 , with land-based and offshore wind being an important part to meet this target (EU, 2019b). The European Union has been at the forefront of wind energy technology development in recent years, especially offshore; European companies represent an impressive $90 \%$ of the offshore global market (EU, 2019a). There is a special focus on offshore wind development in the EU Clean Energy for All Europeans package, in which $30 \%$ of the future electricity demand, approximately $450 \mathrm{GW}$, is expected to be supplied by offshore wind (EU, 2019a) - a huge increase from today's $20 \mathrm{GW}$ of installed capacity (Wind Europe, 2020). In the United States, it has been estimated that wind can supply $35 \%$ of the US electricity demand by 2050, with $86 \mathrm{GW}$ installed offshore (DOE, 2015). Moving from landbased to offshore turbines has also opened possibilities of increasing the size and power of the wind turbine and plant. Deeper-water locations offshore have also been used by floating turbines, with the first floating wind plant in operation since 2017. Such fascinating developments are challenging the technological borders and existing knowledge base of the industry. There is limited experience with such huge machinery in harsh environmental conditions, so the best practices and standards have not yet fully matured.

The drivetrain converts mechanical power to electrical power and transmits the rotor loads to the bedplate and tower. The drivetrain in this context includes the entire power conversion system from the main bearing to the electrical generator and power conversion system. The two main drivetrain configurations and components that characterize them are depicted in Fig. 1. A variety of wind turbine drivetrain technologies are available, with pros and cons for each in terms of cost, weight, size, manufacturing, materials, efficiency, reliability, and operation and maintenance $(\mathrm{O} \& \mathrm{M})$ (Polinder et al., 2006; Arabian-Hoseynabadi et al., 2010; Moghadam and Nejad, 2020; Harzendorf, 2021; Harzendorf et al., 2021). With digitalization expanding in all industries, new opportunities have arisen in the operation phase, including digital O\&M and digital twins. As the age of the installed fleet continues to increase, considerations for lifetime extension and decommissioning are also becoming more important.

This study reviews the state of the art of the drivetrain technology in the wind turbine industry and discusses future development trends. The focus is on conventional and widely used concepts; unconventional designs, such as hydrostatic (Silva et al., 2014) and hydraulic designs, are not discussed. To achieve the aims of this paper, a life cycle approach (Torsvik et al., 2018), as illustrated in Fig. 2, is employed. First, the design - and, to a limited extent, manufacturing - is discussed. It is followed by drivetrain operation - in particular, condition and performance monitoring - and, finally, lifetime extension, decommissioning and recycling.
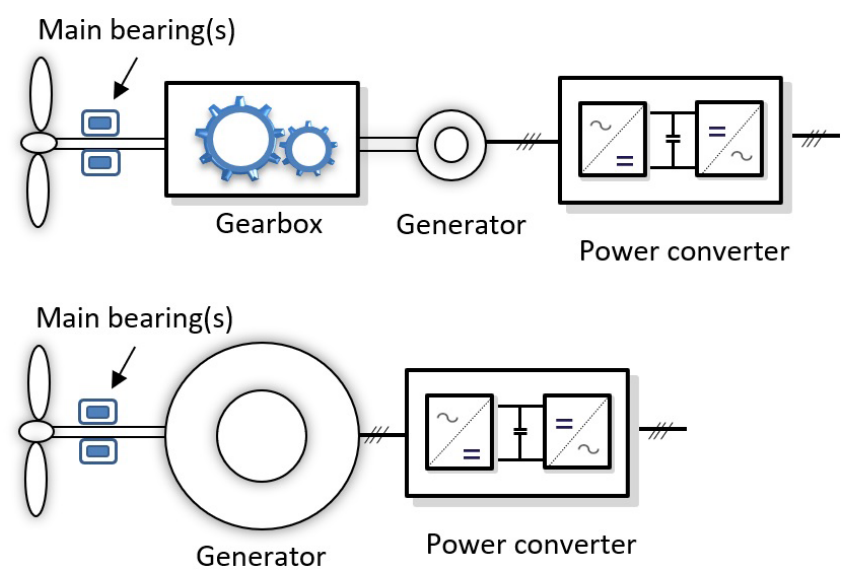

Figure 1. Schematic of the two most common types of drivetrain configurations, with and without a gearbox (illustration by Amir Nejad).

\section{Design trends and developments}

The technological drivers for the drivetrain are not necessarily the same as other elements of the wind turbine. For instance, for towers there are site-specific solutions that depend on wind conditions or other site characteristics, which affect the cost considerably. However for the drivetrain, the number and size of components are cost drivers, not the siteor region-specific characteristics. It is possible to design the drivetrain with respect to logistic costs, for example a modular design that can be handled by a smaller or tower-top crane, reducing transportation, installation and replacement costs for offshore wind turbines, although such technology is still under development. In terms of availability of future drivetrain designs, the development trend is in not only the quality and manufacturing but also the service and operational monitoring.

A compact, lightweight drivetrain is the most costeffective option for large offshore wind turbines because it reduces the nacelle mass and hence tower and foundation or floating platform masses and costs. To achieve these reductions, there has been a trend toward increasing the mechanical integration of the main bearing, gearbox and generator (Stehouwer and van Zinderen, 2016; Demtröder et al., 2019; Nejad and Torsvik, 2021; Reisch, 2021; Zeichfüß1 et al., 2021; Weber and Hansen, 2021). In terms of the power conversion system, permanent magnet synchronous generators (PMSGs) with full-power converter systems are becoming more common than doubly fed induction generators (DFIGs) with partial-power-converter systems. Concerns over the supply of rare-earth materials typically used in PMSGs have also spurred interest in alternate generator technologies, such as superconducting generators (Veers et al., 2020). Regardless of drivetrain design choice, the loads and operational conditions that the drivetrain is subjected to are derived from the design load cases described in the Inter- 


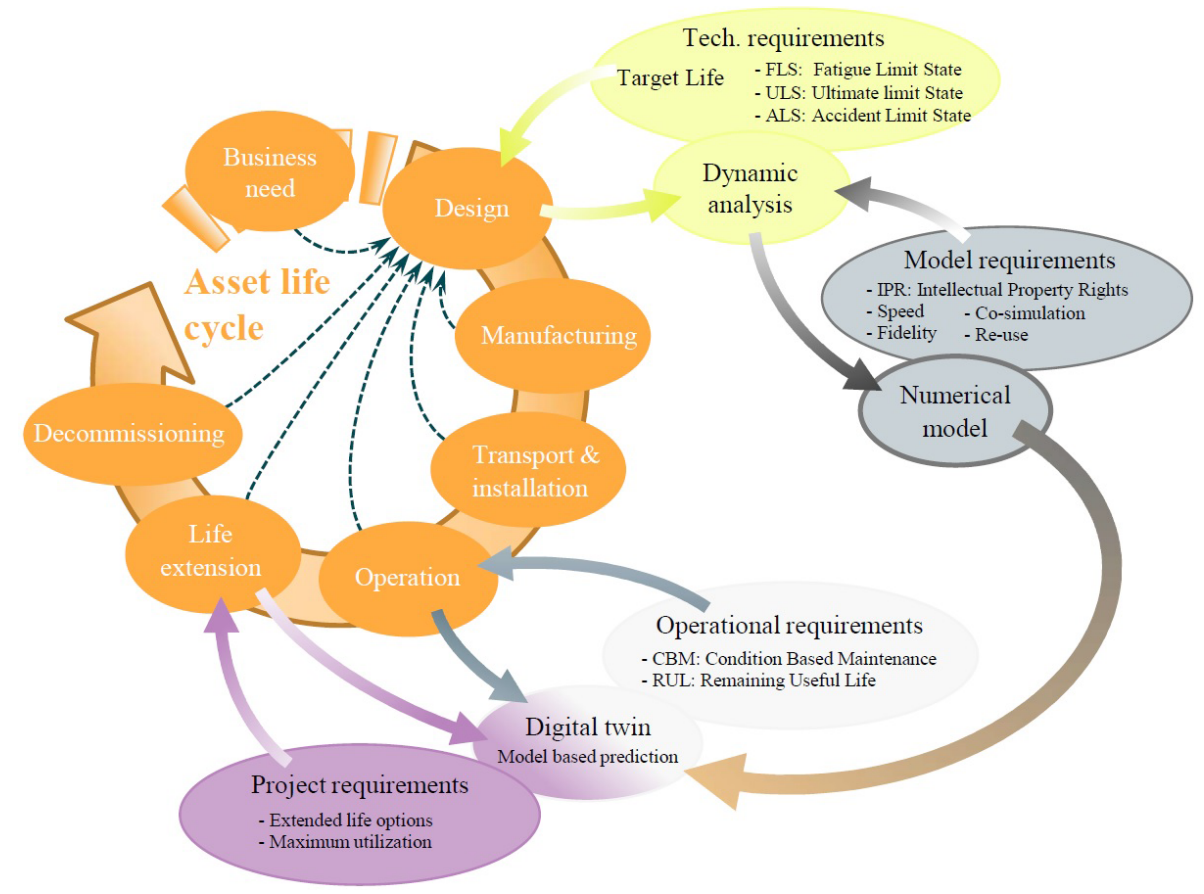

Figure 2. Wind turbine life cycle (Torsvik et al., 2018).

national Electrotechnical Commission (IEC) 61400-1 design standard for land-based wind and IEC 61400-3-1 and IEC 61400-3-2 design standards for offshore fixed and floating wind applications.

\subsection{Main bearing}

Current commercially available main bearing designs use rolling-element bearings (Hart et al., 2020). Spherical roller bearings are utilized in a significant proportion of currently operational main bearings, with usage of this technology likely to continue (to a greater or lesser extent) in sub$5 \mathrm{MW}$ machines. Tapered roller bearing designs are now also common at these power levels. For larger wind turbines ( $\geq 5 \mathrm{MW}$ ), however, the industry has very much converged on tapered roller main bearing technology (Chovan and Fierro, 2021). Because of the large applied nontorque loads, the resulting bearing designs are likewise large in diameter, limited in size only by manufacturing and transportation restrictions. Continued use of rolling-element bearings is likely because it is a familiar technology, albeit with design trends moving outside the envelope of prior experience. A central driver behind the move to large-diameter rollingelement bearing arrangements is the need for cost-effective rotor support solutions. Other existing bearing technologies - such as hydrostatic, air and magnetic bearings - tend to require very rigid support structures or are limited to smaller diameters than would be required by modern wind turbines, although hybrid solutions combining different technologies have been proposed (Shrestha et al., 2010). Given the con- tinued increases in main bearing diameter, understanding the effects of deflections in large-diameter rolling-element bearings is essential, and the current practice of assessing bearing design life through only the conventional calculation methods in the International Organization for Standardization (ISO) standards 76 and 281 and technical specification (TS) 16281 might be insufficient with respect to the resulting service life observed in operation.

Main bearings have been shown to experience repeating, large-scale fluctuations in load, even during normal operation (Hart, 2020). These fluctuations likely increase the risk of other damaging mechanisms (such as roller skidding, surface fatigue, wear and abrasion) not accounted for in fatiguelife calculations. As such, the analysis of the operating conditions of these components has further indicated that current life-assessment standards might be insufficient. Main bearing failure rates of up to $30 \%$ during a 20-year design life have also been reported (Hart et al., 2019). Further work is therefore needed to identify principal drivers of main bearing failures, allowing for the development of appropriate design standards and best practice specific to this component, which, in turn, will lead to improvements in reliability. Guo et al. (2021) investigated one possible driver of main bearing failures, that of axial motion between rollers and raceways. It has previously been hypothesized that such motions may compromise the lubricant film which separates bearing internal surfaces, leading to increased levels of friction and wear. However, from analysis of both field measurements and analytical model outputs it was concluded that axial velocities 
are too small to have any significant influence on lubricant film formation (Guo et al., 2021).

Modern offshore wind plants are high-value assets, and there is an increasing interest in longer design life and lifetime extension. Turbine size and drivetrain arrangement can, however, result in main bearing replacement becoming more difficult and expensive, generally requiring removal of the rotor. Consequently, main bearings will increasingly be regarded as part of the load-carrying structure, with cost implications of failure more severe as a result. A further ramification of increased levels of integration is that main bearing operational requirements become linked to those of other components. For example, in addition to supporting the turbine rotor, some direct-drive configurations require the main bearing to also support the generator rotor while maintaining an appropriate generator air gap. Coupled approaches to the modeling and assessment of wind turbine drivetrain systems will therefore become increasingly important.

Novel main bearing design concepts are also being developed and tested. Loriemi et al. (2021) propose the use of asymmetric spherical roller bearings to improve main bearing internal load sharing during operation. Finite-element modeling was used to compare a standard and asymmetrical design, with results indicating significant improvements for the latter with respect to both main bearing fatigue life and isolation of the gearbox from transferred axial loads. Plain bearing (equivalently, journal bearing) technology is also being considered in this space. More specifically, a segmented plain bearing with conical sliding surfaces is being developed as a main bearing solution for wind turbines (Rolink et al., 2020, 2021). Sliding segments are connected to the housing via doubly flexible supports to maintain their alignment with the tilting shaft and prevent edge loading. A major advantage of this design is that the sliding segments are individually replaceable uptower without requiring drivetrain disassembly. Other main bearing concepts utilizing this same technology have also been explored (Rolink et al., 2020).

With respect to materials, chill-cast nodular cast iron (GJS) has been investigated as a possible alternative to forged steel for manufacture of the rotor-shaft and main bearing seat (Kirsch and Kyling, 2021). Chill-cast GJS enables lightweight construction through freedom of design while also providing appropriately robust mechanical properties. Lighter and smaller hollow rotor-shaft designs may become feasible as a result. This, in turn, would have implications for main bearing design and selection. Cost reductions may therefore be possible through design optimization of GJS components, but resulting shaft-bearing systems can have reduced stiffnesses, which may lead to inner ring creep or fretting fatigue (Kirsch and Kyling, 2021). Work in this area is ongoing.

\subsection{Gearbox}

Wind turbine gearboxes continue to increase in size (up to $3 \mathrm{~m}$ in diameter) and power (up to $15 \mathrm{MW}$ ) (Vaes et al., 2021). With multistage gearboxes using four or more planets per stage, torque densities of $200 \mathrm{~N} \mathrm{~m} \mathrm{~kg}^{-1}$ and speedincreasing ratios up to 200 are now available (Daners and Nickel, 2021). These increasingly flexible systems require detailed modeling to understand the effect of deformations and dynamics on internal loading (Wang et al., 2020). To achieve further cost reductions through economies of scale, modular gearbox designs have been introduced (Windpower, 2021). Gearboxes are designed for a minimum of a 20-year life, as specified in the IEC 61400-4 and American Gear Manufacturers Association (AGMA) 6006 gearbox design standards. Provisions for uptower service or replacement of gearbox components are becoming more common and are required for components that have a design life less than the gearbox. The gearbox system comprises many elements (primarily the rotating shafts, gears and bearings), so the reliability of the gearbox is the product of the reliability of all the failure modes for which there exists a reliability calculation as described in Verband Deutscher Maschinen- und Anlagenbau 23904 and IEC Technical Specification 61400-4-1. But many, if not most, of the failure modes experienced in operation do not have a standardized reliability calculation; hence, as described earlier, there exists a difference between the apparent reliability observed in operation and the calculated design reference reliability. This is not unusual, and it occurs in other industries, although the O\&M cost impact for wind turbines can be more severe. For gearboxes, the reliability calculation considers gear tooth surface durability (pitting) according to ISO 6336-2 and bending strength according to ISO 6336-3, rolling-element bearing rating life from subsurface-initiated fatigue (i.e., rolling contact fatigue) according to ISO 281 and ISO/TS 16281, and shaft fatigue fracture according to Deutsches Institut für Normung 743 and American National Standards Institute (ANSI)/AGMA 6001. In some cases, a safety factor for or percentage risk of these failure modes can at least be quantified in the gearbox design process, including gear tooth scuffing according to ISO/TS 6336-20, ANSI/AGMA 925 and ISO/TS 6336-21 and gear tooth micropitting according to ISO/TS 6336-22, or otherwise assessed for gear tooth flank fracture according to ISO/TS 6336-4. Safety factors for the static strength of gears and bearings are calculated according to ISO 6336 and ISO 76, respectively. Other bearing failure modes, such as surface-initiated fatigue (e.g., micropitting), adhesive wear, corrosion, electrical damage and white-etching cracks, can only be assessed qualitatively. Requirements for materials, processing and manufacture are part of these standards. Further in-depth contact and finite-element analysis are used to design the microgeometry of these rotating components, provide additional rating life calculations (Morales-Espejel and Gabelli, 2017) and analyze the supporting housing struc- 
tures. In addition to classical reliability approaches, use of structural reliability methods for reliability analysis of gears has also been investigated (Nejad et al., 2014a; Dong et al., 2020). Design guidance for the use of plain bearings in the gearbox is under development because they offer advantages in terms of torque density and are life-limited only by wear rather than determined by load-dependent rolling contact fatigue, although they are already becoming common in new gearboxes (Weber and Hansen, 2021; Zeichfüß1 et al., 2021). Surface engineering, lubricants and lubrication of the gearbox also play an essential role in gearbox design, operation and reliability (Dhanola and Garg, 2020; Jensen et al., 2021).

\subsection{Generator}

As highlighted earlier, wind turbine drivetrains can be either geared or direct-drive generator systems (Polinder et al., 2013). The geared generator system can be further divided into either a DFIG with a partial-power converter or a brushless generator with a full-power-converter (GFPC) system. The DFIG system has been the most popular topology for medium-sized turbines ranging from 3-6 MW. The GFPC system uses either a squirrel cage induction generator or a PMSG. Many manufacturers now provide commercial GFPC solutions at power levels up to 10 MW (Siemens, 2020; ABB, 2020). In terms of direct-drive systems, rare-earth PMSGs are appealing for offshore applications. The mainstream power level is from 5-7 MW, but the top power level has kept increasing during the past 2 decades.

The stator elements of DFIGs and PMSGs are largely the same. The major difference in terms of the electrical machine hardware is the rotor design and the means - or lack thereof - of getting current onto and off the rotor. These differences can impact both efficiency and failure mechanisms and their rates. In terms of efficiency, induction generators use a set of currents on the rotor to produce the rotor magnetic field. This leads to joule rotor losses and hence a decrease in efficiency. In contrast, a PMSG uses rare-earth permanent magnets to produce the rotor magnetic field, hence avoiding further joule losses.

In terms of failure types, a DFIG uses carbon brushes and slip rings to conduct the currents between the rotor and the stator. The brushes typically wear out over time and need frequent inspection and replacement. The PMSG avoids those elements. There are also differences in reliability because of the presence of conductor and insulation systems (DFIG) and magnet materials (PMSG), but those are not yet clear. A comparative study of DFIGs and PMSGs showed that during the early life, a PMSG has a failure rate $40 \%$ lower than that of a comparable DFIG (Carroll et al., 2014).

Alongside this variation in the reliability of different electrical machine architectures, there is variation in the reliability caused by the torque rating of the generator. This was first shown by Spinato et al. (2009). For example, it is possible to conceive of two wind turbines that both use the same generator type, but one is in a geared configuration (with a gearbox ratio of 100), and the other is direct-drive. For the same wind turbine rotor (and subsequent power and rotational speed), the torque rating of the direct-drive generator will be 100 times more than that of the geared generator. Assuming that the same electromagnetic shear stress is produced by the two generators, the volume of the direct-drive generator will also be 100 times that of the higher-speed generator. If they have the same ratio of diameter to axial length, then the generator diameter will be $\times \sqrt[3]{100}$ (i.e., $\times 4.64$ ) that of the geared machine. The electromagnetic materials are approximately proportional to the surface area of the rotor and stator. In the case of the low-speed machine, this might be $\times 4.64^{2}$ (i.e., 21.5) times that of the higher-speed machine. With more poles, more coils, longer conductors and insulation, it is likely that the failure rate is higher in direct-drive machines if there is no improvement in failure rate intensity. These variations in generator failure rate should be taken into consideration - along with the gearbox failures discussed in Sect. 2.2 - when assessing failure rates of different types of geared and non-geared drivetrains.

The reliability and availability of the wind generator system have a decisive impact on the cost of energy (COE), especially offshore (Carroll, 2016; Shipurkar et al., 2016). The generator design should consider the interactions with other components to improve the system reliability of the drivetrain (Moghadam and Nejad, 2020). In large wind turbines, multiphase windings with modular converters can be used to improve the generator system availability (Shipurkar et al., 2015; McDonald and Jimmy, 2016).

Upscaling is still a continuing trend for both land-based and offshore wind turbines because a higher-power wind turbine system leads to a lower levelized cost of energy (LCOE) (Sieros et al., 2012). For land-based wind, recent developments include the design of 6 and $8 \mathrm{MW}$ turbines, which will be on the market in the near future, whereas offshore commercial applications now aim for 10-15 MW, and research is going beyond $15 \mathrm{MW}$ (Gaertner et al., 2020; Ashuri et al., 2016; Sartori et al., 2018). Upscaling brings many challenges, including large generator weight, high manufacturing and installation difficulties and cost, complicated electromechanical dynamics, and complexity of system monitoring. A systematic design approach will be required for the design of the generator, where cooling and efficiency will be among the challenges in higher-power systems. Depending on the type, nominal power, shaft speed, the specific electric loading and subsequently the armature thermal loading, three general solutions - namely, air-air, air-water and water jackets - are commercially available to implement the cooling system of a wind generator (Polikarpova, 2014). Significant cost savings can be realized with the development of a more effective stator winding cooling system that further limits the current density to enable the development of higher-power PMSGs of substantially smaller 
diameters while not adversely affecting the electromagnetic performance of the generator.

Multiphase, modular designs are solutions to tackle some of the challenges, and they have been used in commercial systems (Yaramasu et al., 2015; McDonald and Bhuiyan, 2016). Concerns over the availability of rare-earth elements such as neodymium, praseodymium and dysprosium - typically used in PMSGs have led the wind industry and other industries to develop innovative technologies to reduce, substitute for or entirely eliminate their need for generators (Veers et al., 2020). This also results in technologies that are lighter than PMSGs. Breakthroughs in superconducting materials could change the scenario of materials and upscaling completely (Hoang et al., 2018) by eliminating rare earths and enabling further generator weight reductions, with several superconducting generators successfully tested (Frank et al., 2003; Bergen et al., 2019) or in development (Moore, 2020).

The interactions between the generator and power electronics can bring issues including bearing currents, additional stress in insulation because of overvoltage in transients and high-voltage slew rates (Chen et al., 2020); therefore, these interactions should be studied and modeled not only for the design but also for O\&M. Proper filters and control methods should be integrated according to the generator types and power electronics topologies. For the upscaling of wind generators, various modular and multilevel power converter topologies feeding multiphase windings will be a promising solution. But attention should be paid to circulating current and potential asymmetric supplies to avoid risks (Yaramasu et al., 2015).

\subsection{Power converter}

Being between the generator and power grid, the power converter needs to fulfill the requirements for both sides (Blaabjerg et al., 2011). Wind turbine power converters used to have a topology as shown in Fig. 3a, where the generator-side converter is a diode rectifier cascaded with a boost converter to maintain a stable direct current (DC) link voltage; then a two-level inverter is employed on the grid side to ensure full control of the grid current injection (e.g., total harmonic distortion and power factor). This topology has a relatively low cost because of fewer power switches than newer configurations, so it is widely used for generators in small- to medium-sized wind turbines. For megawatt-scale generators, however, the low-frequency torque pulsation and high total harmonic distortion become very harmful to the generator. As a result, the design of the boost converter becomes very challenging, and therefore the front end is then replaced by a two-level, six-switch converter with power factor correction, which is shown in Fig. 3b and is called a back-to-back (BTB) converter. A DFIG with a partially loaded BTB converter is commonly used for generators less than $3 \mathrm{MW}$, whereas a PMSG with a fully loaded BTB converter is commonly used for generators greater than $3 \mathrm{MW}$.
When the power rating is $10 \mathrm{MW}$ or more, a single twolevel BTB converter is no longer suitable because the current stress of the power devices would be extremely high. For two-level BTB converters, the grid-side voltage is typically $690 \mathrm{~V}$. To solve this, multiple two-level BTB converters can be connected in parallel to share the current, whereas the connection of the generator side can be slightly different depending on whether the generator has a multiwinding (see Fig. 4a). Another way to upscale the power rating is to increase it to medium voltage, for instance, by a neutral-pointclamped (NPC) converter (see Fig. 4b) or a modular multilevel converter.

Other crucial topics for power converters include thermal loading and grid integration. Intermittent winds create temperature swings in power converters, which are the main factor of power converter aging. The possibility of applying lithium-ion battery energy storage systems to smooth wind power has been investigated to reduce this aging (Qin et al., 2013). The approach is effective, and the stress mitigation performance is affected by the energy and power rating of the energy storage system; however, the energy storage system's high cost is still the main barrier preventing its widespread application. Variable switching frequencies can also somewhat reduce temperature swings (Qin et al., 2015b), which is an attractive option as a control approach that does not add hardware cost. Nonetheless, the grid filter design to handle the variable switching frequency might be challenging. A promising approach can be the use of the kinetic energy in the wind turbine's rotor as energy storage by the rotating speed control to suppress the power fluctuation in the power converter and thereby reduce the temperature swings (Qin et al., 2015a). Another topic that is trending for the wind power converter is grid integration. Grid-following mode control was applied in the grid-side converter, and it is still mainstream; however, as wind power penetration is increasing, the grid is becoming relatively weak (low short-circuit ratio, low inertia, etc.). Grid-supporting mode control can cause power quality issues and even grid failures in some severe cases (Larumbe et al., 2018, 2019). Energy storage systems or synchronous condensers can be associated with wind plants to provide inertia and to reduce the burden of the grid without grid reinforcement (which is very expensive), but these components are still expensive. Another promising approach is to apply grid-forming mode control to the grid-side wind power converter so the inertia in the wind turbines can be used to support the grid and enhance grid stability and reliability. Grid-forming control is a group of controllers with which the wind power converters not only get the grid current controlled, but also support the grid voltage, frequency or inertia. Typical grid-forming control includes droop control, in which the active and reactive power injected to the grid is reacting to the grid frequency and voltage, and virtual synchronous machine control, in which the inertia of the synchronous machine is mocked in the wind power converter. 

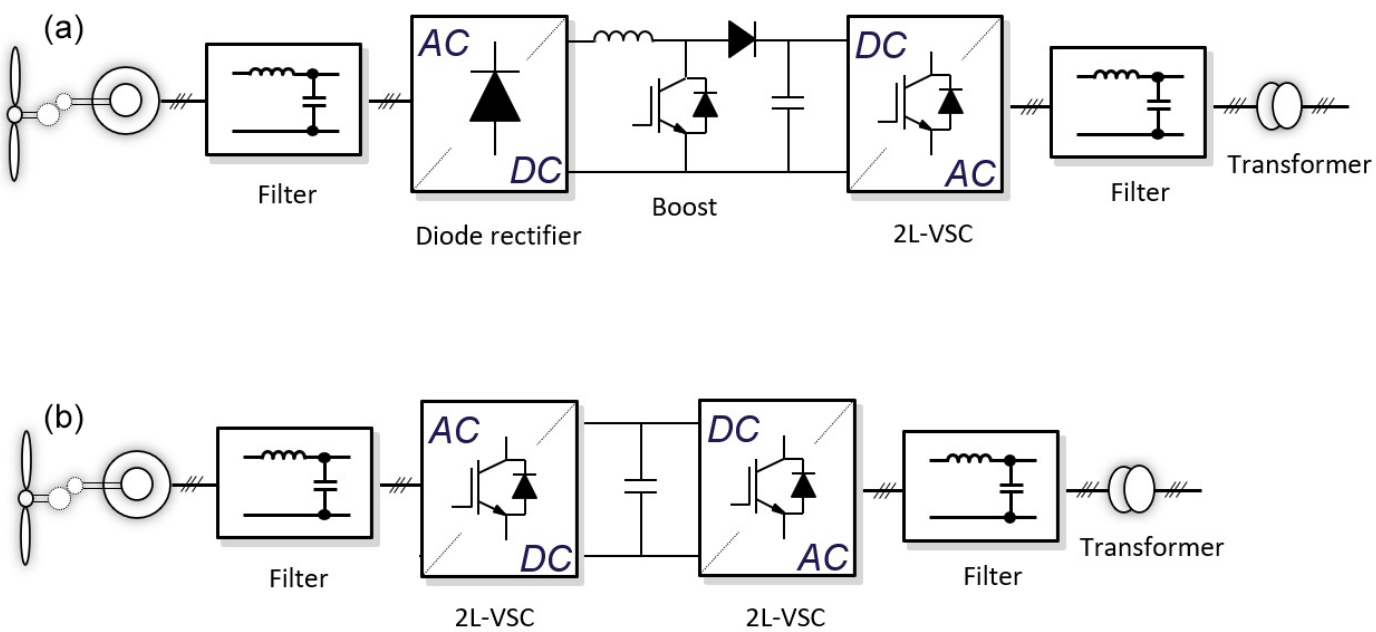

Figure 3. Typical wind power converter topologies from the kilowatt to megawatt scale (Blaabjerg and Ma, 2013). (a) Diode rectifier + boost DC/DC + two-level voltage source converter (VSC). (b) Two-level back-to-back converter. (Illustration by Zian Qin.)

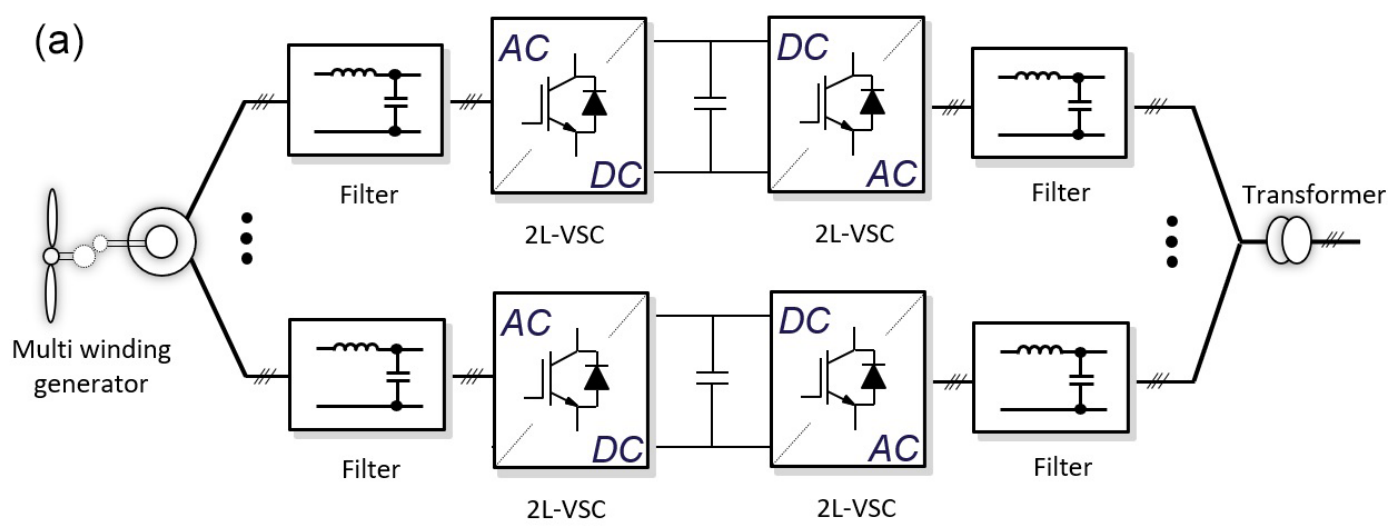

(b)

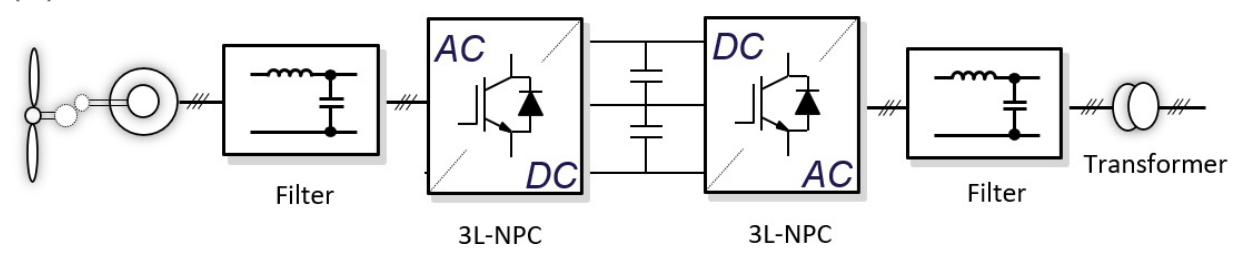

Figure 4. Beyond $10 \mathrm{MW}$ wind power converter topologies. (a) Two-level BTB VSC in parallel. (b) Three-level NPC converter (illustration by Zian Qin).

There is a trend in power electronics to evolve from silicon-based power semiconductors to wide-bandgap devices (e.g., silicon-carbide devices). This will have a positive impact on wind energy systems because it can improve the power density and improve the efficiency of the power converters (Erdman et al., 2015). In the meantime, it also brings challenges to wind generators because of the high-voltage slew rate as a result of fast switching. Proper filtering and oscillation-damping technologies should be used to mitigate the side effects, such as common-mode current and insulation degradation.

The type of cooling system chosen for the converter depends on the nominal power and voltage, power density and thermal design, and generator technology, which can be based on either air or direct or indirect liquid cooling (Zhou et al., 2013). By choosing a liquid cooling system, the size of 
the converter for high-power applications (> 5 MW) can be significantly reduced.

\section{Modeling and analysis}

Wind turbine drivetrains are subject to dynamic loading from a wide range of operating conditions caused by wind shear, veer, turbulence, and gusts; changes in the turbine operational state; grid faults; and nacelle motions; therefore, it is essential that the computational models for the drivetrain consider the dynamics of the rotor and the demands of the grid through the converter. Such an electromechanical model captures the aeroelastic interactions of the rotor and characterizes the voltage and current excursions in the generator because of grid requirements (Gallego-Calderon et al., 2017; Bruce et al., 2015; Blockmans et al., 2013).

Given the complex contact mechanics, one of the most challenging aspects of simulating wind turbine gearboxes is modeling the meshing gear teeth and supporting bearings. With their computational efficiency, lumped-parameter methods have been the method of choice for modeling gears and bearings in system-level, flexible, multibody systems. In this approach, a pair of meshing gears is simplified into a pair of rotating cylinders with constant inertias that are interconnected by a (nonlinear and/or time-varying) spring along the line of action or contact. Analogously, in lumpedparameter bearing modeling, the contact of the rolling elements with the inner and outer bearing raceways is described in terms of nonlinear springs. For meshing gear teeth, the tooth stiffness changes periodically as the number of teeth in contact and the contact locations along the active tooth flanks change throughout the gear rotation, whereas for rolling-element bearings, the stiffnesses vary with the magnitude and the location of the rolling-element contact loads. The various lumped-parameter models differ primarily in the way the contact is computed. One of the oldest but most complete approaches for modeling the interactions between contact surfaces is the classic contact theory by Hertz and its derivatives (Johnson, 1987). Hertzian contact theory is valid (i) when the contact area is sufficiently far from the boundaries of the contacting bodies, allowing them to be treated as elastic half spaces, and (ii) when the elastic deformation of the body is confined to the contact zone. These assumptions have proven to be particularly valid approximations in bearing analysis, where the direct application of Hertzian contact theory has led to computationally efficient and accurate three-dimensional ball bearings (De Mul et al., 1989a; Lim and Singh, 1990). For gears, however, the Hertzian assumptions are not consistent with the comparatively large bending, compressive and shear deformations that are typically encountered in meshing gears. Lumpedparameter gear modeling techniques are therefore typically formulated using mesh stiffnesses that are obtained through empirical formulations (Cai and Hayashi, 1994), analytic techniques based on a combination of linear elasticity theory and Hertzian contact theory (Weber and Banaschek, 1951; Wang et al., 2018), or polynomial curve fits that are derived from finite-element simulations (Kuang and Yang, 1992). Note that these mesh stiffnesses are generally formulated per unit of face width and thus assume a uniform contact force distribution along the face width. In helical gears, however, the contact forces are nonuniformly distributed across the tooth face width, depending on the gear microgeometry, the helix angle and possible gear misalignments. Although three-dimensional lumped-parameter models have been formulated for helical gears (Eritenel and Parker, 2012), a more common approach in wind turbine gearbox modeling - as is also available in a number of commercial, flexible, multibody simulation software packages - is to divide each helical gear into a number spur gear slices and to sum the stiffnesses and/or contact forces of the individual slices (Feng et al., 2018). A similar slicing approach is applied in lumpedparameter roller bearing modeling, where the contact force distribution over the roller surfaces is a nonuniform line load (De Mul et al., 1989b). Note that although lumped-parameter approaches yield reasonably accurate and efficient ball and roller bearing models, contrary to lumped-parameter gear contact models, these bearing models are rarely directly integrated into system-level wind turbine drivetrain models; instead, the models are used to derive linearized stiffness matrices that describe the three-dimensional behavior of the bearing at a selected operating point (Helsen et al., 2011).

Although lumped-parameter models enable the rapid construction and efficient evaluation of gear and bearing models, they lack the modeling complexity required to evaluate dynamic behavior with, for example, gear geometric modifications or housing flexibility. This is desirable, e.g., in the analysis of planetary gear sets, where the flexibility of the ringhousing assembly has a considerable impact on the overall gearbox behavior (Hu et al., 2019). In distributed parameter methods, such as the finite-element method, the full geometric extent of the gear pair is considered, whereas a large part of the lumped-parameter assumptions are replaced by first principles. The increased accuracy of these methods comes at the price of an increased computational cost that is compatible only with static simulations (e.g., computing a linear bearing stiffness matrix (Guo and Parker, 2012) or the stiffness maps of a pair of gears (Palermo et al., 2013)). To alleviate the computational burden of the finite-element method in dynamic simulations, two approaches have recently been introduced. The first approach combines the finite-element method with semi-analytic results from classic contact theory to eliminate the need for highly refined finite-element meshes in the zone of contact (Andersson and Vedmar, 2003; Vijayakar, 1991). The second approach reduces the number of degrees of freedom in the finite-element models by applying model-order-reduction techniques that are specifically tailored toward dynamic contact problems (Blockmans et al., 2015; Fiszer et al., 2016). Given the complexity of these 
methods, however, the usage of finite-element-method-based techniques to model gears and bearings in system-level drivetrain simulations remains largely restricted to the preprocessing phase of the simulation or limited to static simulations. In the absence of complex contact interactions, the modally condensed finite-element method (Craig Jr. and Ni, 1989) becomes a practical means for modeling complex, flexible components such as planet carriers, housings and the bedplate that exhibit relatively low-frequency modal behavior, whereas shafts are commonly represented by Timoshenko beam elements (Struggl et al., 2015). With the increasing size of wind turbines, the flexibility of these components becomes increasingly important because it can significantly affect internal load distributions and vibrations (Helsen et al., 2012). Components with high stiffness-to-mass ratios, on the other hand, are modeled as rigid bodies in which the number of degrees of freedom equals 6 minus the number of applied motion constraints. Couplings such as universal and revolute joints are typically represented by algebraic constraint equations, whereas interference fits, spline couplings and bolted connections are commonly idealized into perfectly homogeneous rigid connections (Marrant et al., 2010). Another modeling approach for spline couplings is to consider rigid in rotation but soft in tilting directions (Guo et al., 2016).

Although significant strides have been made in recent years to increase the accuracy of wind turbine gearbox simulations, a number of challenges remain. With regard to gear and bearing simulation, the modeling of contact-damping phenomena is not nearly as effective and well understood as the modeling of stiffness-related effects despite meritorious contributions in this direction ( $\mathrm{Li}$ and Kahraman, 2013). In addition, the same techniques that resulted in effective lumped-parameter gear contact models have failed to achieve similar results in the field of spline modeling. This is largely because of the relatively large dimensions of the contact zone, rendering Hertzian techniques inaccurate and slicing techniques impractical. With unreduced finite-element-based approaches (Kahn-Jetter and and Wright, 2000) as the main resort, simulations often idealize spline couplings, which can significantly impact the contact load distributions, especially in planetary gear stages. Finally, with the number of gearbox modeling approaches continuously increasing in both the scientific literature and in commercial software, there is a need for identifying and validating the required levels of modeling accuracy in gearbox analyses, including forward dynamic analyses (He et al., 2019), durability analyses (Ding et al., 2018), transfer path analyses (Vanhollebeke et al., 2015) and inverse analyses (Bosmans et al., 2020).

Wind turbine generators can be modeled in different levels of detail, depending on the purpose of the study (Asmine et al., 2010; Ugalde-Loo et al., 2012). When power grid interaction of the wind plants is studied, in which the performance of individual wind turbines is not concerned, the individual generators can be lumped into equivalent machines represented at the collector buses (Kazachkov et al.,
2003). To evaluate the impact of wind turbines on the power grid by simulating power system dynamics, many simplified approaches have been implemented depending on the level of detail required (Slootweg et al., 2003; Akhmatov et al., 2003; Ekanayake et al., 2003; Ullah et al., 2008). For power system design, power flow calculation, short-circuit modeling and power stability analysis, usually positive-sequence or rms models are used, in which electromagnetic transients are neglected (Asmine et al., 2010). In IEC 61400-271:2020, standard electrical simulation models of wind turbine generators for power system and grid stability analysis are described (Göksu et al., 2016). To address electromagnetic transients, e.g., when fault-ride-through strategies are considered, electrical generator models should be built based on their voltage equations (Trevisan et al., 2018). Constant lumped parameters are typically used in these equations. For design and optimization of wind turbine generators, detailed electromagnetic models based on either analytical methods or finite-element methods (FEMs) are necessary. For final design and optimization, FEMs are extensively used (Duan et al., 2010). For detailed analysis of generators under transients, e.g., in a fault run through, a circuitcoupled FEM can be used to consider the parameter variations caused by electromagnetic nonlinearity. Cooling design of generators requires accurate calculation of losses and temperature rises, which is usually carried out by coupled FEMs or thermal-circuit analysis (Bhuiyan and McDonald, 2018; Kowal et al., 2013). As wind turbines grow in size, the electromagneto-mechanical dynamics of the generator and its associated mechanical components should be analyzed in detail to avoid undesirable vibrations. In these analyses, a three-dimensional FEM is sometimes necessary to consider the rotor skewing. The whole machine must be modeled to consider the eccentricity by estimating the radial deformation. Electromagnetic design of large wind generators should consider both the power electronics and mechanical interactions thoroughly, and pole-slot number combination, air-gap length, air-gap radial forces, cogging torque and iron saturations, eigenmodes, and eigenfrequencies should be carefully studied in the electromagneto-mechanical coupling analysis to result in a robust design (Sopanen et al., 2010; Kirschneck et al., 2015; Desmedt et al., 2020).

Similarly, wind power converters can also be modeled from different aspects with different levels of detail. Power loss and thermal models are typically used for selection of power switches, design of the cooling system and reliability studies (Qin et al., 2015b), which is no different from power electronics in other applications. For controller design and ensuring the operation stability, electrical dynamic modeling of the wind power converter is needed, in which the coupled model of the plant, PWM (pulse-width modulation) converter, power filters and power grid is engaged. In earlier stages of control design, the average model of the PWM converter is used to support the less computationally intensive analysis of the controller performance, whereas in later 
stages the full switching model is replaced. For grid impact study, the impedance model of the grid-side wind power converter is usually applied. In the impedance model, the wind power converter is typically modeled as a Norton equivalent, composed of a current source and an output impedance (Larumbe et al., 2021; Vree et al., 2020). The impedance model is especially appropriate for studying the harmonics or stability of a wind plant because the impedance model of a single wind power converter can easily be aggregated into a plant. Not only the power filter but also the control of the wind power converter affects its impedance model, including the current controller, phase lock loop and even the DC link voltage controller.

\section{Operation and maintenance}

O\&M costs represent a sizable and potentially increasing share of the LCOE, especially as wind's LCOE declines because of reduced upfront costs and improved performance. Recent data suggest that O\&M can account for around $25 \%$ of the LCOE for onshore installations (Renewable Energy Agency, 2012; Wiser et al., 2019; Steffen et al., 2020; Ren et al., 2021) and more than $35 \%$ for offshore installations (Carroll et al., 2017; Röckmann et al., 2017; Ren et al., 2021). Downtime must also be considered. Additionally, increased availability might not lead to reduced O\&M costs offshore because vessel type costs must also be considered for turbine repair. For example, crew transfer vessels have much lower costs than jack-up vessels.

The maintenance paradigm is shifting from reactive, periodic time or usage-based maintenance to reliability-centered (or predictive) condition maintenance supported by digital twins as elaborated in Sect. 5.3. If the turbines do not have dedicated condition-monitoring systems, some anomaly detection or fault diagnosis can be conducted based on the turbine supervisory control and data acquisition (SCADA) system data, for which the main purpose is operational control.

\subsection{Condition monitoring and fault detection}

Condition monitoring is an umbrella term that spans various different ways of tracking the health state of a machine in which typically vibration, temperatures, oil contamination or electrical signatures from the generator are used as input signals (Fu et al., 2017; Qiao and Qu, 2018). By using appropriate analysis methods, system changes caused by damaged components (e.g., flaking of bearing raceways) or faulty system states (e.g., water contamination) can be identified. A recent review of the condition monitoring of drivetrains is offered by Helsen (2021). The following sections discuss the two most commonly used types of condition monitoring for wind turbine drivetrains along with the acoustic emissions approach.

\subsubsection{SCADA-based condition monitoring}

Wind turbine SCADA systems produce hundreds of channels of data concerning the operation of a turbine based on multiple installed sensors. In reality, only a small fraction of these data provide valid information that can be used for condition monitoring, and there is a significant challenge in how to extract which information is important. SCADA data in wind turbines are typically sampled at around $1 \mathrm{~Hz}$ and averaged every $10 \mathrm{~min}$. From a condition-monitoring point of view, these data can serve as a low-cost potential solution because no extra sensors are required. The entire list of parameters tracked in the SCADA data is typically quite extensive, but an overview of basic SCADA parameters is given in Table 1. Normally, the extent and quality of the SCADA data depend on the turbine manufacturer, though IEC 61400-25 is used as a common protocol for data collection and labeling of parameters. Other possible uses besides condition monitoring include power curve analysis (Lydia et al., 2014) and modeling with, for example, $k$-nearest neighbors (Kusiak et al., 2009), spare part demand forecasting (Tracht et al., 2013) and load monitoring (Wächter et al., 2015). Angular velocity measurements from SCADA have also been used for fault detection and remaining useful life (RUL) (Nejad et al., 2014b, 2018; Moghadam and Nejad, 2021, 2022).

To analyze SCADA data, machine learning techniques are often employed. One classification of machine learning techniques for wind turbine condition monitoring is to divide them into supervised (classification and regression) and unsupervised (clustering) learning. An example of classification for fault detection, isolation and failure mode diagnosis on the gearbox is illustrated by Koukoura et al. (2019), whereas Turnbull et al. (2019) applied a combination of clustering and classification techniques to group similar operating conditions and detect generator faults. An example of regression to detect anomalies in vibration indicators can be found in Verstraeten et al. (2019). The authors use Bayesian ridge regression to fit linear parameters and inherent noise to the observed data while maintaining the uncertainty over the parameters. This way the model can distinguish between expected and anomalous behavior while capturing the stochasticity of the parameters. In Helsen et al. (2018), an ensemble of models is used to classify bearing temperature data in normal and anomalous behavior. An extensive review of machine learning approaches applied to wind turbines can be found in Stetco et al. (2019).

Other researchers, for example Tautz-Weinert and Watson (2016), categorize the different SCADA-based monitoring methods into five classes: trending, clustering, normal behavior modeling (NBM), damage modeling, and assessment of alarms and expert systems.

i. Trending. A very straightforward approach is to monitor the SCADA parameters over a long period of time and to use statistical thresholds for alarming. 
Table 1. Overview of some basic SCADA parameters (based on Tautz-Weinert and Watson, 2016; Yang et al., 2013, 2014; Godwin and Matthews, 2013; Garcia et al., 2006; Zaher et al., 2009; Catmull, 2011; Watson et al., 2011; Schlechtingen et al., 2013; Wilkinson et al., 2014; and Sun et al., 2016).

\begin{tabular}{ll}
\hline Category & SCADA parameter \\
\hline Environmental & Wind speed, wind direction, ambient temperature, nacelle temperature \\
\hline Electrical & $\begin{array}{l}\text { Active power output, power factor, reactive power, generator voltages, gener- } \\
\text { ator phase current, voltage frequency }\end{array}$ \\
\hline Control variables & $\begin{array}{l}\text { Pitch angle, yaw angle, rotor shaft speed, fan speed and status, generator } \\
\text { speed, cooling pump status, number of yaw movements, set pitch angle and } \\
\text { deviation, number of starts and stops, operational status code }\end{array}$ \\
\hline Temperatures & $\begin{array}{l}\text { Gearbox bearing, gearbox lubricant oil, generator winding, generator bear- } \\
\text { ing, main bearing, rotor shaft, generator shaft, generator slip ring, inverter } \\
\text { phase, converter cooling water, transformer phase, hub controller, top con- } \\
\text { troller, converter, controller, grid busbar }\end{array}$ \\
\hline
\end{tabular}

ii. Clustering. When large numbers of wind turbines need to be monitored efficiently, it becomes imperative to have an automatic manner to classify the turbines as "healthy" or "faulty." Examples of clustering can be found in Kusiak and Zhang (2010), in which drivetrain and tower accelerations are analyzed using SCADA data by means of a modified $k$-means clustering conditioned on the wind speed. Kim et al. (2011) and Catmull (2011) applied self-organizing maps instead of $k$-means to build such clusters. Despite these advancements, the interpretation of the clustering results is often still perceived to be difficult (Tautz-Weinert and Watson, 2016).

iii. NBM. NBM employs the same idea of anomaly detection as the previous techniques, but it focuses more on the empirical modeling of the measurements. The residual error between the modeled and observed parameter then serves as a health indicator. A basic example of NBM involves the use of linear and polynomial models. A linear autoregressive model with exogenous inputs was used by Garlick et al. (2009) to detect generator bearing failures from the bearing temperature. Higherorder polynomial full-signal reconstruction models of drivetrain temperatures were developed by Wilkinson et al. (2014) to detect gearbox and generator failures. A popular form of NBM is to track changes in the power curve as a function of wind speed. Faults such as problems with blade pitching can change the shape of the curve, though how to detect changes in the power curve, which can show a significant degree of variation even under normal conditions, is a challenge. A method which has shown promise is to use a Gaussian process (GP) model, e.g., Zhou et al. (2014); Manobel et al. (2018); Pandit and Infield (2018b). Such a model is able to fit an accurate power curve to noisy data which can then be used to predict future power values against which observed values can be compared. Pandit et al.
(2019) showed that multivariate input GP models incorporating both wind speed and air density were especially suitable for this purpose. In addition to power, GP models can also be used to monitor other parameters such as blade pitch angle and rotational speed (Pandit and Infield, 2018a).

iv. Damage modeling. Instead of training empirical normal behavior models, the measurements can be interpreted with physical models to improve the accuracy. Gray and Watson (2010) developed a damage model using physical failure modes of interest to estimate the failure probability. A general scheme for a physics-based monitoring approach was proposed by Breteler et al. (2015).

v. Assessment of alarms and expert systems. The last class looks at the outputs of the SCADA control alarms or the NBM output alarms. A typical example of this class is the analysis of the status codes of the wind turbine. Status code processing approaches typically investigate the possibility of extracting useful, actionable information about the health of the turbine from these status codes, and there exist many different ways to do this. For example, Chen et al. (2012) used a probabilistic approach with Bayesian networks to track down root causes for failures such as a pitch fault. Qiu et al. (2012) also used Bayes' theorem and compared the extracted patterns using a Venn diagram. Other approaches often involve machine learning, such as Kusiak and Li (2011), who used neural network ensembles to predict status codes and their severity to detect a malfunction. Lastly, a significant amount of research examines the use of "expert" systems to interpret the status codes or model outputs. Often these systems are based on using fuzzy logic to determine a diagnosis for anomalies. Example research works that are based on or employ fuzzy logic are given in Garcia et al. (2006); Schlechtingen et al. (2013); Sun 
et al. (2016); Cross and Ma (2015); Li et al. (2013), and $\mathrm{Li}$ et al. (2014).

\subsubsection{Vibration-based condition monitoring}

In general, vibration-based condition monitoring is by far the most prevalent and widely used method, largely because of its ease of instrumentation and its reliable response to damage development (Randall, 2011). First, the majority of all vibration signal-processing techniques have some requirement of stationarity. In most cases, stationarity in time is required for harmonic frequencies such that spectrum-based approaches are not invalidated because of frequency smearing. Wind turbines, however, are far from stationary machines because the wind dictates the rotation speed of the rotor. This speed fluctuation leads to time-varying harmonic frequencies of the vibration sources, such as gears, shafts or bearings. Knowledge of the speed is therefore crucial for many signal-processing methods because this speed fluctuation needs to be compensated or considered. A common, accurate and reliable way to gain this speed information is through the installation of an angle encoder or tachometer on one of the rotating shafts in the gearbox. An alternative is to estimate the instantaneous angular speed directly from the vibration signal itself. An overview and comparison of the state of the art in vibration-based rotation speed estimation can be found in Peeters et al. (2019) and Leclère et al. (2016).

From a statistical point of view, gear vibration signals are considered deterministic because the gears are locked in place and do not exhibit random slippage like bearings. On the other hand, bearing vibrations are regarded as stochastic in nature because of the random slippage of the roller elements, and they are normally characterized as being second-order cyclostationary, meaning they have a periodic autocorrelation. This distinction in statistical characteristics provides an opportunity for signal-processing methods to separate gear from bearing signals; therefore, a common follow-up step to angular resampling is employing a signal separation technique, such as discrete or random separation (Antoni and Randall, 2004b), self-adaptive noise cancellation (Antoni and Randall, 2004a), linear prediction filtering (Sawalhi and Randall, 2004), the (generalized) timesynchronous average (Abboud et al., 2017, 2016), or cepstrum editing (Peeters et al., 2018). Alternative signal separation methods - such as (ensemble) empirical mode decomposition (Huang et al., 1998; Wu and Huang, 2009), principal component analysis or variational mode decomposition (Dragomiretskiy and Zosso, 2013) - can isolate signal subspaces in the vibration, but these subspaces are typically not guaranteed to have any relevance to mechanical components because they do not employ any prior physical knowledge.

After preprocessing the vibration signal, the last step involves the identification of potential faults. Current practice in condition-monitoring systems often revolves around tracking time-domain statistical indicators (de Azevedo et al., 2016; Lu et al., 2009; Tchakoua et al., 2014). Examples of some commonly used time-domain indicators are given in Ali et al. (2018); Zhu et al. (2014); D'Elia et al. (2015); Večeř et al. (2005); Rai and Upadhyay (2016); Sharma and Parey (2016); Decker et al. (1994); Zakrajsek et al. (1993), and Bozchalooi and Liang (2007). These time indicators can all be used to characterize trends in measured vibration signals.

The main reason why spectral methods are so popular in condition monitoring is that they allow for not only fault detection but also fault diagnosis. For gears, approaches for fault detection usually focus more on tracking the amplitudes of harmonics and sidebands in the spectrum or the cepstrum, whereas for bearings more cyclostationarity-based methods tend to be employed. Nonetheless, for gear faults it is also recommended to look at the cyclostationary signature of a signal because distributed gear faults can significantly impact the modulation of the deterministic gear signals. A local fault on one of the gear teeth will introduce low-level sidebands in the spectrum, whereas distributed gear damage exhibits higher-level sidebands.

The presence of modulation sidebands is also the main reason why cepstrum-based techniques are popular for gear diagnostics. Because the cepstrum groups together equally spaced harmonics, it provides a very effective means to track the average amplitude of the sidebands. A summary of methods applied for the diagnosis of a faulty gearbox is presented in Sheng (2012).

The most popular approach for the analysis of secondorder cyclostationary signals (and, correspondingly, for bearing diagnostics) is envelope analysis. The envelope of a signal is considered to be any function that "encloses" the energy variation in the signal. By taking the modulus of the analytic version of the signal, obtained through the Hilbert transform, the envelope time waveform can be found (given that the envelope frequency of interest respects Bedrosian's theorem; Bedrosian, 1963). Usually the envelope is squared (effectively done by multiplying the analytic signal with its conjugate) before taking the Fourier transform to analyze its envelope spectrum (Ho and Randall, 2000).

\subsubsection{Acoustic emissions condition monitoring}

To detect strong nonstationary signals such as sudden crack propagation, using acoustic emissions could be a suitable solution. This technology has already been proven for crack detection on pressure tanks, and its applicability for monitoring of rotating components is being researched with promising results. For example, rolling bearings have been exposed to critical operating conditions, such as high-friction lubrication regimes, overloading or high angular accelerations, which were successfully detected and differentiated using an acoustic-emissions-based detection scheme (Couturier and Mba, 2008; Cockerill et al., 2016; Cornel et al., 2018, 2020). 
Further, acoustic emissions have been successfully used for the detection of subsurface cracks in bearings with a response time up to $55 \%$ earlier than classic vibration-based detection (Cornel et al., 2021). Further investigations are being carried out to assess the economic value of this earlier response. Nonetheless, there are still several challenges to be addressed, such as filtering ambient noise or differentiation between individual and overlapping signals of individual components like bearings, gears and couplings.

A further complex but promising challenge of bearing condition monitoring is linking different data acquisition techniques, such as monitoring acoustic emissions and electrical effects or using SCADA data (de Azevedo et al., 2016). To overcome this and the aforementioned challenges, two key aspects need to be addressed in further research:

- fault diagnosis algorithm - the distinct feature extraction of specific fault mechanisms in real-world applications in nonstationary operating conditions, including the integration between condition-monitoring systems; the estimation of the RUL; and new methods of signal analysis, such as machine learning;

- sensor selection and placement - the distinct, transferable description of the influence of fault-mechanismspecific components inside a complex mechanical system on the system's vibration behavior.

Further, each gearbox has a different behavior; therefore, the first step to reach dynamic system condition monitoring is to obtain reliable characteristic information from the system behavior.

\subsection{Remaining useful life}

The term "consumed life" of a component is a metric that can be calculated based on existing rating methods by using actual loads (whereas design loads are used in the development phase), while "remaining life" is the best estimation of how long a component will survive, which requires statistical prediction models. The consumed life calculation of drivetrain mechanical components, such as bearings and gears, requires the analysis of measurements from the field, such as gearbox temperatures, bearing vibration measurements and wind turbine operational measurements. Such measurements can be continuous online recordings or measurements taken during inspections such as oil quality sampling. Typical indicators for the consumption of the life of the gearbox are

- the number of particles in the gearbox oil per time duration or the particulates in the grease for greased bearings (Feng et al., 2013),

- the size of the particles in the oil;

- the frequency of the oil temperature or bearing temperature excursions above a threshold (Feng et al., 2013);
- changes in vibration spectrum signatures.

The distribution of particulates in the oil or grease can be analyzed in a laboratory to identify the chemicals present and thereby their source to determine their origin from the bearings or gears.

With advanced multibody simulation tools, it is also possible to model all elements of the drivetrain fully coupled to the aeroelastic interactions of the rotor (Gallego-Calderon and Natarajan, 2015; Gallego-Calderon et al., 2017; Wang et al., 2020) and mounted on a flexible tower. In such a software tool, the drivetrain is subject to continuous wind-driven excitation and grid-driven events. If the response of the drivetrain in terms of the bearing displacements and shaft loads is validated with the physical turbine during different operating conditions, then the software tool can be used to track fatigue damage consumption in the drivetrain by supplying it with measured operating conditions from the physical turbine. This also requires specific drivetrain component failure modes to be tracked in the simulation, such as the occurrences of bearing roller sliding (Dabrowski and Natarajan, 2017) or the vibration excitation of different components. Monitoring fatigue damage growth also provides knowledge of the remaining useful life of the drivetrain if the design life of the components of the drivetrain are known (Doner, 2020). Monitoring systems and modeling tools are also increasingly being integrated with supply chain management systems to reduce downtime and O\&M costs (Nordmark and Boyeye, 2021).

Moreover, the inverse methods can also be employed to estimate the loads on drivetrain components from SCADA and vibration measurements and can be used to estimate the component fatigue damage and RUL (Mehlan et al., 2021). Dynamic models of the drivetrain might be needed in some cases if not enough data or measurements are available that can be developed provided that basic information about the drivetrain (e.g., geometry, bearing types and gear teeth numbers) is known (van Binsbergen et al., 2021).

\subsection{Lifetime extension}

Once a turbine reaches its 20-year design life, there are, in principle, three options that can be considered by the operator: decommissioning, full repowering or lifetime extension (Tartt et al., 2021). Full repowering and lifetime extension can accomplish the goal of extending the service life of existing wind turbines. The main benefit is to increase returns on investments and reduce the levelized cost of energy for wind power. Full repowering refers to the dismantling of old wind turbines and replacing them with new ones. Lifetime extension, on the other hand, refers to the assessment of the remaining useful life and possible turbine component upgrades while keeping the turbine hub height, size or plant layout unchanged. Partial repowering or refurbishment (Topham and McMillan, 2017) is another term used in the industry for re- 
placing and upgrading the components; this can be considered an option in the lifetime extension process.

Whether and how to conduct lifetime extension is a complex decision-making process and depends on many factors, including technical, economical and legal factors (Ziegler et al., 2018). The prerequisite is that the turbine's structural integrity - e.g., foundation, tower, nacelle and hub - has been assessed and can be safely used throughout the expected turbine lifetime extension span. Sometimes these assessments also include blades, which, if not strong enough, could be upgraded as well. Specific to drivetrain components, typical practices are replacing them with newer products - e.g., gearboxes, main bearings or generators - which have improved performance and reliability. On the other hand, from the drivetrain research-and-development perspective, some opportunities lie in reliability assessment and driving event identification, which can benefit from fault diagnostics and RUL prediction research conducted to support wind plant O\&M. The expected outputs are more accurate and reliable drivetrain component integrity assessment based on historical data or inspection as well as prediction throughout the planned lifetime extension period. Should the evaluation be positive with an acceptable confidence level, the drivetrain components might not be replaced, as is currently practiced now, and additional costs of the turbine lifetime extension can be reduced.

Tartt et al. (2021) investigated the lifetime extension practices in other industries and proposed a methodology for wind turbine drivetrains. The industry's experience with lifetime extension is still limited. Also, different markets - e.g., Europe or the United States - might require different strategies. There are a few uncertainty concerns: (i) technically, how trustworthy the integrity assessment of the structural components is; (ii) economically, how the assumed future electricity prices might hold true; and (iii) legally, how related policies might change.

\subsection{Decommissioning and recycling}

Wind turbines are typically decommissioned and recycled at least partially - at the end of their service life because of both their salvage value and local legislative requirements, so decommissioning has increasingly become part of the planning process (Jensen, 2019). Detailed discussions on the decommissioning process for land-based and offshore wind turbines, recycling analysis of different turbine subsystems, basic cost analysis, and the environmental impacts can be found in Jensen (2019). The main challenges surrounding the decommissioning process of wind plants are the regulatory framework, the overall planning of the process, the transportation logistics and the environmental impacts (Topham et al., 2019a).

Studies show that recycling after decommissioning can pay back some of the decommissioning costs (Topham et al., $2019 b)$. The main parts of the drivetrain from the recycling perspective are the bearings, gears, frames, shafts, couplings, windings, cores (generator stator and rotor), permanent magnets, hydraulic cooling systems and electronics. Windings are made of copper. Cores are made of electrical steel lamination, which is an iron alloy to which silicon is added. Bearings, gears, frames, shafts and couplings are made of different types of alloy steel. Permanent magnets used in wind turbine PMSGs are often NdFeB magnets. Hydraulics are considered less problematic because the recycling industry is accustomed to handling the related components. Reuse of lubricants is also being explored (SKF, 2021). Electronics are usually difficult to recycle because of their complex material composition. Nearly all waste electronics equipment is currently shredded, and further physical processes, including magnetic and electrostatic techniques, are applied to separate different metal fractions. Two main methods are used to recycle these components: shredding and disassembling. The method used depends on the recycled component, the size and the material. Recycling can be supported by robotics and using optimization models to optimize the process (Rassõlkin et al., 2018). Separate parts of disassembled components are reused if they do not have any damage. The rest are remelted as the same raw material or to a new alloy.

High-volume drivetrain recycling needs to minimize environmental impact (no harmful chemicals or emissions or energy-intensive processes) and have high recovery rates of rare and precious materials while still being economically viable. Recycling can also be in the design phase. For example, surface-mounted PMSGs compared to interior rotor magnets have different disassembling procedures. Modular design can also offer a clear advantage in recycling because healthy parts can be separately reused in other components of that type.

Further, the use of recycled material can lead to cheaper new products (Gabhane and Kaddoura, 2017), which, apart from being more environmentally friendly, can be a good motivation for recycling. Recycling and reusing can also contribute to reducing the potential supply chain risk, especially for rare-earth materials (Habib and Wenzel, 2014).

\section{Emerging areas}

Three areas - drivetrains in floating turbines, drivetrains and plant considerations, and digitalization - are considered to be emerging areas. Veers et al. (2019) have highlighted "aerodynamics, structural dynamics, and offshore wind hydrodynamics of enlarged wind turbines" as one of the grand challenges in wind energy science. Floating wind turbines are then specially pointed out because of additional degrees of freedom and motions. Understanding the turbine responses and interaction with the wind flow in the plant is also emphasized (Veers et al., 2019). Moreover, digitalization has in recent years changed the societies. According to the EU's dig- 
ital strategy, digitalization is one of the medium-term challenges facing the EU (EU, 2018).

\subsection{Drivetrain in floating turbines}

Drivetrains in floating wind turbines are exposed to different dynamic loads than those on bottom-fixed or land-based ones. Apart from the wind loads, the wave-induced motions can affect the drivetrain load responses. The wave-induced motions can have a negative impact on the main bearing fatigue life - particularly on the one carrying axial loads - as highlighted by Nejad et al. (2015). Sethuraman et al. (2014) investigated the effects of the floating wind turbine motion on direct-drive generator air-gap integrity and showed that the air-gap stability of the generator is more sensitive to magnetic forces if the supporting frame is relatively rigid. They also highlighted the need for air-gap management for directdrive generators on floating platforms.

A recent full-scale experimental field study of a $6 \mathrm{MW}$ drivetrain on a spar floating substructure (Torsvik et al., 2021) indicates that the effect of wave-induced motions might not be as significant as the wind loading on the drivetrain responses, particularly in larger turbines. A set of strain measurements on the main bearing show that the effect of wave motions is negligible compared with the tower shadow excitation (Torsvik et al., 2021).

The study by Nejad and Torsvik (2021) investigated the lessons learned in the last 10 years with regard to drivetrains on floating wind turbines. Among other things, the study highlighted that the maximum tower-top axial acceleration might not be a reasonable limiting factor for the fatigue life of main bearings in floating wind turbines, at least for a spar-type floating turbine (Nejad et al., 2019). It also emphasized that a flexible bedplate influences the main bearing and components inside the gearbox, and therefore the coupling effects between the structure and the drivetrain need to be considered in floating wind turbines, particularly in compact design concepts. Given the limited experience with floating wind turbines, however, more research is needed.

\subsection{Drivetrain and plant consideration}

Wakes induced by other turbines in the plant cause increased turbulence and thus can affect the loading on the drivetrain (Roscher et al., 2017). How the wakes are controlled at the plant level will therefore influence the drivetrain design life (van Binsbergen et al., 2020). Several approaches which have recently been proposed to reduce overall plant losses by reducing wake effects employ either some form of static or dynamic induction control or wake steering by yaw control (Andersson et al., 2021). Static induction control aims to reduce the strength of the wake of an upstream machine by changing the pitch of the blades or the rotational speed of the rotor in such a way as to reduce the thrust at the expense of some efficiency but to allow downstream machines to see an increased wind speed so that the combined output of the turbines is increased. However, in practice, little gain is seen using this approach (Bartl and Sætran, 2016). Dynamic induction control seeks to increase wake mixing and thus reduce plant losses by periodically pitching the blades during each rotor rotation (Frederik et al., 2020). Wake steering takes a different approach, whereby an upstream turbine is deliberately yawed out of the prevailing wind direction (again slightly reducing turbine efficiency) with the aim of ensuring that downstream machines are out of its wake, thus increasing their output and increasing overall plant efficiency (Fleming et al., 2017) but also affecting shaft torque and blade moments (Damiani et al., 2018). Wake steering typically does not have large effects on the drivetrain of the upstream turbine, whereas an increase in the yaw angle would lead to an increase in the drivetrain load variation in the downstream turbine (van Binsbergen et al., 2020). In contrast, increases in blade pitch angle associated with static induction control would reduce the standard deviations of the drivetrain dynamic response of the upstream wind turbine, whereas it would not significantly affect the standard deviations in the downstream turbine (van Binsbergen et al., 2020).

Based on the study performed by van Binsbergen et al. (2020), the wake impact on the downstream turbine can reduce the lifetime of the first main bearing of the drivetrain by $17 \%$, and it can reduce the turbine power intake by $30 \%$. The mitigation of loads on the drivetrain of the wind turbine and an increase in power capture at the turbine level are addressed in the literature on turbine control by optimizing the generator torque, blade pitch and yaw steering controls (as shown in, for example, van Binsbergen et al., 2020, and Fleming et al., 2013). Optimized wind power plant management by considering the influence of wakes was recently studied by Andersson and Imsland (2020).

The optimized plant control design to maximize the wind plant power intake and simultaneously minimize the degradation of the drivetrain components influenced by wake loads is still an open research problem. The latter calls for highfidelity models of wake flow and wake loads on the drivetrain of downstream turbines and the drivetrain system to study the drivetrain load effects and responses and, finally, the derivation of sufficient drivetrain-lifetime-related constraints that can be integrated into the plant stochastic model predictive control design framework. From this perspective, the additional role of wind plant control is to distribute accumulated fatigue evenly over the drivetrains of different turbines to improve the reliability of the plant.

\subsection{Drivetrain and digitalization}

The use of digital technologies and digitized data can support wind turbine drivetrain analyses at both the system and component levels, for instance by receiving and transmitting real-time data through the data acquisition and transmission layers; by storing and processing data through the platform 
layer; and, finally, by decision support through the application layer (An et al., 2021). For this purpose, digitalization targets the sensors and actuators installed on the drivetrain and the other turbine systems - such as the site network, servers and even smart phones (André et al., 2021) - that are connected to the turbine's and plant's control and monitoring systems to improve reliability, availability, quality of service and user experience.

Digital twin models can support the drivetrain's design and operation. Digital twin in this context includes sensors (data collection), models (dynamic and degradation models) and decision support platform (e.g., estimation of remaining useful life) (Johansen and Nejad, 2019). Computationally inexpensive digital twin models can support the predictive maintenance of drivetrain system components by monitoring the remaining useful lifetime of the critical components (e.g., the gears of the gearbox) in real time (Moghadam and Nejad, 2022). Using the existing physical models, integrating them in a unified framework, applying signal-processing techniques to estimate these models and model inputs in real time from available measurements, optimizing the data streaming between models, using continuous processing architectures, and using statistical approaches and stochastic modeling techniques to model and mitigate the impact of uncertainties are the tasks under the umbrella of a digital twin. The risk associated with digital twin implementation, specially in terms of wrong decision support, should also be considered (Ibrion et al., 2019). In general, challenges of digital twin models mainly arise from the following (Moghadam et al., 2021):

- finding the minimum or appropriate model fidelity required to capture the dynamics of the component for different operation and failure modes for a wide range of drivetrain components

- optimizing data streaming between models and data processing algorithms and continuously processing architectures to deal with the real-time aspects of digital twin models

- developing a preprocessing stage to model and mitigate the different sources of uncertainty and to verify and ensure time synchronicity when the data come from different sources and when dealing with the different sample rates.

To overcome these challenges, merging edge computing with the Internet of Things (IoT) can play a significant role. Using distributed computing algorithms supported by edge computing data-handling architectures (e.g., fog computing) has been recently adapted from computer science for wind plant control and monitoring systems to significantly reduce the computational burden of implementing digital twin models' complex algorithms to monitor drivetrain components in future wind turbine O\&M analyses (Verstraeten et al., 2019).
By using fog computing, it is possible to break the digital twin into simple subproblems with less computational complexity, and each one can be executed on a fog. The IoT can provide real-time access to data in each network node with the possibility of using the processing and storage capacities of the nodes for control and monitoring purposes, and not all data in fogs need to be shared with other fogs or even the cloud. Cybersecurity frameworks should be deployed at the communication network and the computing modules to guarantee the integrity, authenticity, confidentiality and availability of the data while they are being transmitted over the network nodes. Because future wind plants' control and monitoring systems will need to handle more voluminous, heterogeneous data and distributed features, but storage and processing capacities are limited, the IoT can significantly improve turbine control and monitoring.

\section{Summary and concluding remarks}

This paper presents the state of the art and future development trends for wind turbine drivetrain technologies from the life cycle perspective. Lighter and more compact design concepts are the most cost-effective option, particularly for large offshore turbines. As a result, the integration of electromechanical systems together with the main bearing has been a recent trend. For land-based applications, geared drivetrains seem to be the dominant technology; however, the race between geared or not is still ongoing for offshore, with medium-speed (or hybrid concept) or even high-speed geared drivetrains under development for large offshore wind turbines. The extensive research and development of gearbox and bearing design has mainly been on improving reliability by better understanding the failure modes in operation on one hand and, on the other hand, on the development of new technologies, e.g., plain bearings. The mediumspeed concepts have shown to be a promising compromise between high-speed and direct-drive designs, whereas highspeed, multistage gearboxes have also been a research focus in recent years. For offshore turbine generators, there has been a recent increasing trend toward direct-drive systems and PMSGs with full-power converter systems rather than DFIGs with partial-power-converter systems. Superconducting generators are also seen as an attractive alternative to PMSGs because of the large quantity of rare-earth materials needed for PMSGs.

Given the criticality of drivetrain components in wind turbines, condition-based maintenance is seen as an essential element, at least for offshore and large turbines. In newer and larger turbines, greater than $2.5 \mathrm{MW}$ or $3 \mathrm{MW}$, most if not all have dedicated condition-monitoring systems, which typically monitor the gearbox, main bearings and generator. Their outputs can be used to support anomaly detection, fault diagnostics and prognostics models. These models can be data-driven, physics-based or hybrid, integrating both data- 
and physics-domain models. In the data domain, particularly for SCADA-based condition monitoring, machine learning and artificial intelligence technologies are being actively investigated for wind turbine applications.

Condition-monitoring technologies deployed for wind turbine drivetrains are generally good at fault diagnostics, especially for high-speed components. The performance of various solutions in terms of prognostics still needs to improve, which presents an opportunity to bridge progress made by the research community. On the other hand, the industry has long been eager to obtain accurate predictions of component remaining useful life, which is one objective of typical fault prognostics. Among the various drivetrain subcomponents, bearing faults have shown to be prevalent and have been actively investigated by both industry and researchers.

As the industry moves farther offshore and into deeper water, increasing numbers of floating wind turbines are expected to be used. The early lessons highlight differences in terms of dynamic behavior and life of the drivetrain in floating wind turbines compared with fixed ones, especially for the main bearings. As offshore turbine sizes are increasing, the component flexibility and potential dynamic coupling effects should not be overlooked during design modeling and analysis.

Another emerging area of research for drivetrains is digitalization. Apart from data processing and digital models, data handling, ownership, security, communication and transfer at the scale of large wind plants are also interesting challenges. The use of digital twins for condition monitoring is also a recent research direction.

In summary, the grand challenges in drivetrain research discussed in this paper include load and load effects of drivetrains in large wind turbines as well as floating ones, influence of wake and farm control, generator technologies and use of rare-earth materials, employing prognostics to improve reliability, and use of advances in digitalization such as digital twin models. Addressing these challenges calls for more interdisciplinary research and collaborations to improve wind turbine drivetrain reliability and availability with the main aim to reduce the cost of energy over time.

Data availability. No data sets were used in this article.

Author contributions. This paper was initiated by ARN and JH. ARN coordinated and led the article writing; creation of the structure; writing of the abstract, introduction and conclusion; and gathering and editing of inputs from all listed co-authors. The final edit was carried out by ARN and JK together.

Competing interests. The contact author has declared that neither they nor their co-authors have any competing interests.
Disclaimer. Publisher's note: Copernicus Publications remains neutral with regard to jurisdictional claims in published maps and institutional affiliations.

Acknowledgements. This paper has been prepared by the Drivetrain Technical Committee (DTC) at the European Academy of Wind Energy (EAWE) over the period of 2020-2021. The authors appreciate the fruitful discussions within the DTC and acknowledge the EAWE for facilitating this forum for the wind research community. The open-access publication was financially supported by the NTNU Publishing Fund and the Marine Technology Department at the NTNU, which are greatly acknowledged.

This work was also authored in part by the National Renewable Energy Laboratory, operated by the Alliance for Sustainable Energy, LLC, for the US Department of Energy (DOE) under contract no. DE-AC36-08GO28308. Funding was provided by the US Department of Energy Office of Energy Efficiency and Wind Energy Technologies Office. The views expressed herein do not necessarily represent the views of the DOE or the US Government. The US Government retains and the publisher, by accepting the article for publication, acknowledges that the US Government retains a nonexclusive, paid-up, irrevocable, worldwide license to publish or reproduce the published form of this work, or allow others to do so, for US Government purposes.

Edward Hart is funded by a Brunel Fellowship from the Royal Commission for the Exhibition of 1851.

Pieter-Jan Daems, Timothy Verstraeten, Cédric Peeters and Jan Helsen received funding from the Flemish Government (AI Research Program). They would like to acknowledge the FWO (Fonds Wetenschappelijk Onderzoek) for their support through the SB grant of Timothy Verstraeten (no. 1S47617N) and post-doctoral grant of Cédric Peeters (no. 1282221N). They would also like to acknowledge VLAIO for the support through the SIM MaDurOS program project SBO MaSiWEC (H.B.C.2017.0606) and Blauwe Cluster ICON project Supersized 4.0.

Financial support. This research has been partially supported by the US Department of Energy (grant no. DE-AC36-08GO28308), the Royal Commission for the Exhibition of 1851 (grant no. 1851) and the Fonds Wetenschappelijk Onderzoek (grant nos. 1S47617N and $1282221 \mathrm{~N})$.

Review statement. This paper was edited by Katherine Dykes and reviewed by two anonymous referees.

\section{References}

ABB: Generators for wind turbines - Generators । ABB, https://new.abb.com/motors-generators/generators/ generators-for-wind-turbines (last access: 15 September 2021), 2020.

Abboud, D., Antoni, J., Sieg-Zieba, S., and Eltabach, M.: Deterministic-random separation in nonstationary regime, J. Sound Vib., 362, 305-326, 2016. 
Abboud, D., Antoni, J., Sieg-Zieba, S., and Eltabach, M.: Envelope analysis of rotating machine vibrations in variable speed conditions: A comprehensive treatment, Mech. Syst. Signal Pr., 84, 200-226, 2017.

Akhmatov, V., Nielsen, A. H., Pedersen, J. K., and Nymann, O.: Variable-speed wind turbines with multi-pole synchronous permanent magnet generators. Part I: Modelling in dynamic simulation tools, Wind Engineering, 27, 531-548, 2003.

Ali, J. B., Saidi, L., Harrath, S., Bechhoefer, E., and Benbouzid, M.: Online automatic diagnosis of wind turbine bearings progressive degradations under real experimental conditions based on unsupervised machine learning, Appl. Acoust., 132, 167-181, 2018.

An, J., Zou, Z., Chen, G., Sun, Y., Liu, R., and Zheng, L.: An IoTBased Life Cycle Assessment Platform of Wind Turbines, Sensors, 21, 1233, https://doi.org/10.3390/s21041233, 2021.

Andersson, A. and Vedmar, L.: A dynamic model to determine vibrations in involute helical gears, J. Sound Vib., 260, 195-212, 2003.

Andersson, L. E. and Imsland, L.: Real-time optimization of wind farms using modifier adaptation and machine learning, Wind Energ. Sci., 5, 885-896, https://doi.org/10.5194/wes-5-885-2020, 2020.

Andersson, L. E., Anaya-Lara, O., Tande, J. O., Merz, K. O., and Imsland, L.: Wind farm control - Part I: A review on control system concepts and structures, IET Renewable Power Generation, 15, 2085-2108, https://doi.org/10.1049/RPG2.12160, 2021.

André, H., Leclere, Q., Anastasio, D., Benaïcha, Y., Billon, K., Birem, M., Bonnardot, F., Chin, Z., Combet, F., Daems, P. J., Daga, A. P., De Geest, R., Elyousfi, B., Griffaton, J., Gryllias, K., Hawwari, Y., Helsen, J., Lacaze, F., Laroche, L., Li, X., Liu, C., Mauricio, A., Melot, A., Ompusunggu, A., Paillot, G., Passos, S., Peeters, C., Perez, M., Qi, J., Sierra-Alonso, E. F., Smith, W. A., and Thomas, X.: Using a smartphone camera to analyse rotating and vibrating systems: Feedback on the SURVISHNO 2019 contest, Mech. Syst. Signal Pr., 154, 107553, https://doi.org/10.1016/j.ymssp.2020.107553, 2021.

Antoni, J. and Randall, R.: Unsupervised noise cancellation for vibration signals: part I evaluation of adaptive algorithms, Mech. Syst. Signal Pr., 18, 89-101, 2004a.

Antoni, J. and Randall, R.: Unsupervised noise cancellation for vibration signals: part II a novel frequency domain algorithm, Mech. Syst. Signal Pr., 18, 103-117, 2004b.

Arabian-Hoseynabadi, H., Tavner, P., and Oraee, H.: Reliability comparison of direct-drive and geared-drive wind turbine concepts, Wind Energy: An International Journal for Progress and Applications in Wind Power Conversion Technology, 13, 62-73, 2010.

Ashuri, T., Martins, J. R., Zaaijer, M. B., van Kuik, G. A., and van Bussel, G. J.: Aeroservoelastic design definition of a $20 \mathrm{MW}$ common research wind turbine model, Wind Energy, 19, 20712087, 2016.

Asmine, M., Brochu, J., Fortmann, J., Gagnon, R., Kazachkov, Y., Langlois, C.-E., Larose, C., Muljadi, E., MacDowell, J., Pourbeik, P., Seman, S. A., and Wiens, K.: Model validation for wind turbine generator models, IEEE Transactions on Power Systems, 26, 1769-1782, 2010.

Bartl, J. and Sætran, L.: Experimental testing of axial induction based control strategies for wake control and wind farm optimization, J. Phys.: Conference Series, 753, 032035, https://doi.org/10.1088/1742-6596/753/3/032035, 2016.

Bedrosian, E.: A product theorem for Hilbert transforms, Proc. IEEE, 51, 868-869, 1963.

Bergen, A., Andersen, R., Bauer, M., Boy, H., Brake, M. T., Brutsaert, P., Bührer, C., Dhallé, M., Hansen, J., ten Kate, H., Kellers, J., Krause, J., Krooshoop, E., Kruse, C., Kylling, H., Pilas, M., Pütz, H., Rebsdorf, A., Reckhard, M., Seitz, E., Springer, H., Song, X., Tzabar, N., Wessel, S., Wiezoreck, J., Winkler, T., and Yagotyntsev, K.: Design and in-field testing of the world's first ReBCO rotor for a $3.6 \mathrm{MW}$ wind generator, Superconductor Sci. Technol., 32, 125006+12, https://doi.org/10.1088/13616668/ab48d6, 2019.

Bhuiyan, N. A. and McDonald, A.: Optimization of offshore direct drive wind turbine generators with consideration of permanent magnet grade and temperature, IEEE T. Energy Conver., 34, 1105-1114, 2018.

Blaabjerg, F. and Ma, K.: Future on power electronics for wind turbine systems, IEEE J. Em. Sel. Top. P., 1, 139-152, 2013.

Blaabjerg, F., Liserre, M., and Ma, K.: Power electronics converters for wind turbine systems, IEEE T. Ind. Appl., 48, 708-719, 2011.

Blockmans, B., Helsen, J., Vanhollebeke, F., and Desmet, W.: Dynamic response of a multi-megawatt wind turbine drivetrain under voltage dips using a coupled flexible multibody approach, in: International Design Engineering Technical Conferences and Computers and Information in Engineering Conference, vol. 55928 , p. V005T11A045, American Society of Mechanical Engineers, 2013.

Blockmans, B., Tamarozzi, T., Naets, F., and Desmet, W.: A nonlinear parametric model reduction method for efficient gear contact simulations, Int. J. Numer. Meth. Eng., 102, 1162-1191, 2015.

Bosmans, J., Vanommeslaeghe, Y., Geens, L., Fiszer, J., Croes, J., Kirchner, M., Denil, J., De Meulenaere, P., and Desmet, W.: Development and embedded deployment of a virtual load sensor for wind turbine gearboxes, in: Journal of Physics: Conference Series, vol. 1618, p. 022011, IOP Publishing, 2020.

Bozchalooi, I. S. and Liang, M.: A smoothness index-guided approach to wavelet parameter selection in signal de-noising and fault detection, J. Sound Vib., 308, 246-267, 2007.

Breteler, D., Kaidis, C., Tinga, T., and Loendersloot, R.: Physics based methodology for wind turbine failure detection, diagnostics \& prognostics, EWEA 2015 Annual Event, 2015.

Bruce, T., Long, H., and Dwyer-Joyce, R. S.: Dynamic modelling of wind turbine gearbox bearing loading during transient events, IET Renew. Power Gen., 9, 821-830, 2015.

Cai, Y. and Hayashi, T.: The linear approximated equation of vibration of a pair of spur gears (theory and experiment), J. Mech. Design, 116, 558-564, 1994.

Carroll, J.: Cost of energy modelling and reduction opportunities for offshore wind turbines, Ph.D. thesis, University of Strathclyde, 2016.

Carroll, J., McDonald, A., and McMillan, D.: Reliability comparison of wind turbines with DFIG and PMG drive trains, IEEE T. Energy Conver., 30, 663-670, 2014.

Carroll, J., McDonald, A., Dinwoodie, I., McMillan, D., Revie, M., and Lazakis, I.: Availability, operation and maintenance costs of offshore wind turbines with different drive train configurations, Wind Energy, 20, 361-378, 2017. 
Catmull, S.: Self-organising map based condition monitoring of wind turbines, in: EWEA Annual Conf, vol. 2011, 14-17 March 2011, Brussels, Belgium, 2011.

Chen, B., Tavner, P. J., Feng, Y., Song, W. W., and Qiu, Y.: Bayesian network for wind turbine fault diagnosis, EWEA Annual Conf, vol 2012, Copenhagen, Denmark, 16-19 April 2012, 2012.

Chen, X., Xu, W., Liu, Y., and Islam, M. R.: Bearing Corrosion Failure Diagnosis of Doubly Fed Induction Generator in Wind Turbines Based on Stator Current Analysis, IEEE T. Ind. Electron., 67, 3419-3430, https://doi.org/10.1109/TIE.2019.2917418, 2020.

Chovan, C. and Fierro, A. J.: Improving Bearing Life in Wind Turbine Main Shafts and Gearboxes, Tech. rep., Timken, https://www.timken.com/resources/timken-tdi-bearings-whitepaper-improving-bearing-life-in-wind-turbine-main-shafts-andgearboxes/ (last access: 10 September 2021), 2021.

Cockerill, A., Clarke, A., Pullin, R., Bradshaw, T., Cole, P., and Holford, K.: Determination of rolling element bearing condition via acoustic emission, P. I. Mech. Eng. J.-J. Eng., 230, 1377-1388, 2016.

Cornel, D., Guzmán, F. G., Jacobs, G., and Neumann, S.: Acoustic response of roller bearings under critical operating conditions, Tech. rep., World Congress on Engineering Asset Management, Stavanger, 2018.

Cornel, D., Guzmán, F. G., Jacobs, G., and Neumann, S.: Acoustic response of roller bearings under critical operating conditions, in: Engineering Assets and Public Infrastructures in the Age of Digitalization, pp. 740-749, Springer, ISBN 978-3-030-48021-9, 2020.

Cornel, D., Gutiérrez Guzmán, F., Jacobs, G., and Neumann, S.: Condition monitoring of roller bearings using acoustic emission, Wind Energ. Sci., 6, 367-376, https://doi.org/10.5194/wes6-367-2021, 2021.

Couturier, J. and Mba, D.: Operational bearing parameters and acoustic emission generation, J. Vib. Acoust., 130, 024502, https://doi.org/10.1115/1.2776339, 2008.

Craig Jr., R. R. and Ni, Z.: Component mode synthesis for model order reduction of nonclassicallydamped systems, J. Guid. Control Dynam., 12, 577-584, 1989.

Cross, P. and Ma, X.: Model-based and fuzzy logic approaches to condition monitoring of operational wind turbines, International Journal of Automation and Computing, 12, 25-34, 2015.

Dabrowski, D. and Natarajan, A.: Identification of loading conditions resulting in roller slippage in gearbox bearings of large wind turbines, Wind Energy, 20, 1365-1387, 2017.

Damiani, R., Dana, S., Annoni, J., Fleming, P., Roadman, J., van Dam, J., and Dykes, K.: Assessment of wind turbine component loads under yaw-offset conditions, Wind Energ. Sci., 3, 173-189, https://doi.org/10.5194/wes-3-173-2018, 2018.

Daners, D. and Nickel, V.: More torque is better than torque: Higher torque density for gearboxes, in: Conference for Wind Power Drives 2021: Conference Proceedings, 9-11 March 2021, Aachen, Germany, 2021.

de Azevedo, H. D. M., Araújo, A. M., and Bouchonneau, N.: A review of wind turbine bearing condition monitoring: State of the art and challenges, Renewable and Sustainable Energy Reviews, 56, 368-379, 2016.

De Mul, J., Vree, J., and Maas, D.: Equilibrium and associated load distribution in ball and roller bearings loaded in five degrees of freedom while neglecting friction - Part I: general theory and application to ball bearings, J. Tribol., 111, 142-148, 1989a.

De Mul, J., Vree, J., and Maas, D.: Equilibrium and associated load distribution in ball and roller bearings loaded in five degrees of freedom while neglecting friction - Part II: application to roller bearings and experimental verification, J. Tribol., 111, 149-155, 1989b.

Decker, H. J., Handschuh, R. F., and Zakrajsek, J. J.: An enhancement to the NA4 gear vibration diagnostic parameter, NASA Technical Report ARL-TR-389 Prepared for the 18th Annual Meeting sponsored by the Vibration Institute, Hershey, Pennsylvania, 20-23 June 1994, US, 1994.

D’Elia, G., Cocconcelli, M., Rubini, R., and Dalpiaz, G.: Evolution of gear condition indicators for diagnostics of planetary gearboxes, in: The International Conference Surveillance 8, FRA, 2015.

Demtröder, J., Kjaer, P., and Hansen, A.: Balancing Incremental Development and Disruptive Innovation in the Design of a Modularized, Scalable Powertrain for the Modular Windturbine Product System EnVentus, in: Dresdner Maschi-nenelemente Kolloquium, Technische Universität Dresden, ISBN 13 978-3-96548055-1, 2019.

Desmedt, M., Dong, J., Wani, F., Bauer, P., and Polinder, H.: Electromechanical dynamics analysis of pole-piece rotors in pseudo direct-drive wind turbine generators, in: 2020 International Conference on Electrical Machines (ICEM), vol. 1, pp. 1889-1895, IEEE, 2020.

Dhanola, A. and Garg, H.: Tribological challenges and advancements in wind turbine bearings: A review, Eng. Fail. Anal., 118, 1861-1863, 2020.

Ding, F., Tian, Z., Zhao, F., and Xu, H.: An integrated approach for wind turbine gearbox fatigue life prediction considering instantaneously varying load conditions, Renew. Energ., 129, 260-270, 2018.

DOE: Wind Vision: A New Era for Wind Power in the United States, Tech. Rep. DOE/GO-102015-4557, U.S. Department of Energy, 2015.

Doner, S.: LCOE optimization in wind farms: How the digital gearbox can increase reliability and predict remaining useful lifetime for wind turbine drive trains, in: Drivetrain Reliability Collaborative Meeting, 19 February 2020, Golden, Colorado, US, 2020.

Dong, W., Nejad, A. R., Moan, T., and Gao, Z.: Structural reliability analysis of contact fatigue design of gears in wind turbine drivetrains, J. Loss Prevent. Proc., 65, 104115 , https://doi.org/10.1016/j.jlp.2020.104115, 2020.

Dragomiretskiy, K. and Zosso, D.: Variational mode decomposition, IEEE T. Signal Proces., 62, 531-544, 2013.

Duan, G., Wang, H., Guo, H., and Gu, G.: Direct drive permanent magnet wind generator design and electromagnetic field finite element analysis, IEEE T. Appl. Supercon., 20, 1883-1887, 2010.

Ekanayake, J. B., Holdsworth, L., Wu, X., and Jenkins, N.: Dynamic modeling of doubly fed induction generator wind turbines, IEEE T. Power Syst., 18, 803-809, 2003.

Erdman, W., Keller, J., Grider, D., and VanBrunt, E.: A 2.3MW Medium-Voltage, Three-Level Wind Energy Inverter Applying a Unique Bus Structure and 4.5-kV Si/SiC Hybrid Isolated Power Modules, in: 2015 IEEE Applied Power Electronics Conference, 15-19 March 2015, Charlotte, NC, USA, https://doi.org/10.1109/APEC.2015.7104513, 2015. 
Eritenel, T. and Parker, R. G.: Three-dimensional nonlinear vibration of gear pairs, J. Sound Vib., 331, 3628-3648, 2012.

EU: EUROPEAN COMMISSION DIGITAL STRATEGY, A digitally transformed, user-focused and data-driven Commission, https://ec.europa.eu/info/sites/default/files/file_import/ digitally-transformed_user-focused_data-driven_commission_ en.pdf (last access: 15 September 2021), 2018.

EU: Onshore and offshore wind, https://ec.europa.eu/energy/topics/ renewable-energy/onshore-and-offshore-wind_en, last access: 14 August 2020a.

EU: A European Green Deal, https://ec.europa.eu/info/strategy/ priorities-2019-2024/european-green-deal_en, last access: 14 August 2020b.

Feng, M., Ma, H., Li, Z., Wang, Q., and Wen, B.: An improved analytical method for calculating time-varying mesh stiffness of helical gears, Meccanica, 53, 1131-1145, 2018.

Feng, Y., Qiu, Y., Crabtree, C., Long, H., and Tavner, P.: Monitoring wind turbine gearboxes, Wind Energy, 16, 728-740, 2013.

Fiszer, J., Tamarozzi, T., and Desmet, W.: A semi-analytic strategy for the system-level modelling of flexibly supported ball bearings, Meccanica, 51, 1503-1532, 2016.

Fleming, P., Annoni, J., Shah, J. J., Wang, L., Ananthan, S., Zhang, Z., Hutchings, K., Wang, P., Chen, W., and Chen, L.: Field test of wake steering at an offshore wind farm, Wind Energ. Sci., 2, 229-239, https://doi.org/10.5194/wes-2-229-2017, 2017.

Fleming, P. A., Van Wingerden, J.-W., Scholbrock, A. K., Van der Veen, G., and Wright, A. D.: Field testing a wind turbine drivetrain/tower damper using advanced design and validation techniques, in: 2013 American Control Conference, pp. 2227-2234, IEEE, 2013.

Frank, M., Frauenhofer, J., van Hasselt, P., Nick, W., Neumueller, H., and Nerowski, G.: Long-term operational experience with first Siemens $400 \mathrm{~kW}$ HTS machine in diverse configurations, IEEE T. Appl. Supercon., 13, 2120-2123, 2003.

Frederik, J. A., Weber, R., Cacciola, S., Campagnolo, F., Croce, A., Bottasso, C., and van Wingerden, J.-W.: Periodic dynamic induction control of wind farms: proving the potential in simulations and wind tunnel experiments, Wind Energ. Sci., 5, 245257, https://doi.org/10.5194/wes-5-245-2020, 2020.

Fu, L., Wei, Y., Fang, S., Zhou, X., and Lou, J.: Condition monitoring for roller bearings of wind turbines based on health evaluation under variable operating states, Energies, 10, 1564, https://doi.org/10.3390/en10101564, 2017.

Gabhane, P. and Kaddoura, M.: Remanufacturing in Circular Economy-A Gearbox Example, Master thesis, Division of Environmental Systems Analysis, Chalmers University of Technology, https://hdl.handle.net/20.500.12380/252053, 2017.

Gaertner, E., Rinker, J., Sethuraman, L., Zahle, F., Anderson, B., Barter, G. E., Abbas, N. J., Meng, F., Bortolotti, P., Skrzypinski, W., Scott, G., Feil, R., Bredmose, H., Dykes, K., Shields, M., Allen, C., and Viselli, A.: IEA wind TCP task 37: Definition of the IEA 15-megawatt offshore reference wind turbine, Tech. rep., National Renew. Energ. Lab. (NREL), Golden, CO (United States), 2020.

Gallego-Calderon, J. and Natarajan, A.: Assessment of wind turbine drive-train fatigue loads under torsional excitation, Eng. Struct., 103, 189-202, 2015.
Gallego-Calderon, J., Natarajan, A., and Cutululis, N. A.: Ultimate design load analysis of planetary gearbox bearings under extreme events, Wind Energy, 20, 325-343, 2017.

Garcia, M. C., Sanz-Bobi, M. A., and Del Pico, J.: SIMAP: Intelligent System for Predictive Maintenance: Application to the health condition monitoring of a windturbine gearbox, Comput. Ind., 57, 552-568, 2006.

Garlick, W. G., Dixon, R., and Watson, S. J.: A model-based approach to wind turbine condition monitoring using SCADA data, Proceedings of the Twentieth International Conference on Systems Engineering, Coventry, UK, 8-10 September 2009, 2009.

Godwin, J. L. and Matthews, P.: Classification and detection of wind turbine pitch faults through SCADA data analysis, International Journal of Prognostics and Health Management, 4, 90 100, 2013.

Göksu, Ö., Altin, M., Fortmann, J., and Sørensen, P. E.: Field validation of IEC 61400-27-1 wind generation type 3 model with plant power factor controller, IEEE T. Energy Conver., 31, 11701178, 2016.

Gray, C. S. and Watson, S. J.: Physics of failure approach to wind turbine condition based maintenance, Wind Energy, 13, 395-405, 2010.

Guo, Y. and Parker, R. G.: Stiffness matrix calculation of rolling element bearings using a finite element/contact mechanics model, Mech. Mach. Theory, 51, 32-45, 2012.

Guo, Y., Lambert, S., Wallen, R., Errichello, R., and Keller, J.: Theoretical and experimental study on gear-coupling contact and loads considering misalignment, torque, and friction influences, Mech. Mach. Theory, 98, 242-262, 2016.

Guo, Y., Bankestrom, O., Bergua, R., Keller, J., and Dunn, M.: Investigation of main bearing operating conditions in a three-Point mount wind turbine drivetrain, Forsch. Ingenieurwesen, 85, 405415, 2021.

Habib, K. and Wenzel, H.: Exploring rare earths supply constraints for the emerging clean energy technologies and the role of recycling, J. Clean. Prod., 84, 348-359, 2014.

Hart, E.: Developing a systematic approach to the analysis of timevarying main bearing loads for wind turbines, Wind Energy, 23, 2150-2165, 2020.

Hart, E., Turnbull, A., Feuchtwang, J., McMillan, D., Golysheva, E., and Elliott, R.: Wind turbine main-bearing loading and wind field characteristics, Wind Energy, 22, 1534-1547, 2019.

Hart, E., Clarke, B., Nicholas, G., Kazemi Amiri, A., Stirling, J., Carroll, J., Dwyer-Joyce, R., McDonald, A., and Long, H.: A review of wind turbine main bearings: design, operation, modelling, damage mechanisms and fault detection, Wind Energ. Sci., 5, 105-124, https://doi.org/10.5194/wes-5-105-2020, 2020.

Harzendorf, F.: Geared vs. direct drive - a holistic system comparison, in: Conference for Wind Power Drives 2021: Conference Proceedings, 9-11 March 2021, Aachen, Germany, 2021.

Harzendorf, F., Schelenz, R., and Jacobs, G.: Reducing cost uncertainty in the drivetrain design decision with a focus on the operational phase, Wind Energ. Sci., 6, 571-584, https://doi.org/10.5194/wes-6-571-2021, 2021.

He, G., Ding, K., Wu, X., and Yang, X.: Dynamics modeling and vibration modulation signal analysis of wind turbine planetary gearbox with a floating sun gear, Renew. Energ., 139, 718-729, 2019. 
Helsen, J.: Review of Research on Condition Monitoring for Improved O\&M of Offshore Wind Turbine Drivetrains, Acoust. Aust., 49, 251-258, https://doi.org/10.1007/s40857-021-002372, 2021.

Helsen, J., Vanhollebeke, F., Marrant, B., Vandepitte, D., and Desmet, W.: Multibody modelling of varying complexity for modal behaviour analysis of wind turbine gearboxes, Renew. Energ., 36, 3098-3113, 2011.

Helsen, J., Vanhollebeke, F., Vandepitte, D., and Desmet, W.: Some trends and challenges in wind turbine upscaling, in: Proceedings of ISMA International Conference On Noise And Vibration 2012, vol. 6, pp. 4345-4359, Katholieke Univ Leuven, Dept Werktuigkunde, 2012.

Helsen, J., Peeters, C., Verstraeten, T., Verbeke, J., Gioia, N., and Nowé, A.: Fleet-wide condition monitoring combining vibration signal processing and machine learning rolled out in a cloudcomputing environment, in: International Conference on Noise and Vibration Engineering (ISMA), 17-19 September 2018, Leuven, Belgium, 2018.

Ho, D. and Randall, R.: Optimisation of bearing diagnostic techniques using simulated and actual bearing fault signals, Mech. Syst. Signal Proces., 14, 763-788, 2000.

Hoang, T.-K., Quéval, L., Berriaud, C., and Vido, L.: Design of a 20-MW Fully Superconducting Wind Turbine Generator to Minimize the Levelized Cos of Energy, IEEE T. Appl. Supercon., 28, 1-5, https://doi.org/10.1109/TASC.2018.2810309, 2018.

Hu, Y., Talbot, D., and Kahraman, A.: A Gear Load Distribution Model for a Planetary Gear Set With a Flexible Ring Gear Having External Splines, J. Mech. Design, 141, 053301, https://doi.org/10.1115/1.4041583, 2019.

Huang, N. E., Shen, Z., Long, S. R., Wu, M. C., Shih, H. H., Zheng, Q., Yen, N.-C., Tung, C. C., and Liu, H. H.: The empirical mode decomposition and the Hilbert spectrum for nonlinear and nonstationary time series analysis, P. Roy. Soc. Lond. A Mat., 454, 903-995, 1998.

Ibrion, M., Paltrinieri, N., and Nejad, A. R.: On risk of digital twin implementation in marine industry: Learning from aviation industry, in: Journal of Physics: Conference Series, vol. 1357, p. 012009, IOP Publishing, 2019.

Jensen, J. P.: Evaluating the environmental impacts of recycling wind turbines, Wind Energy, 22, 316-326, 2019.

Jensen, O. L., Heuser, L., and Petersen, K. E.: Prevention of "white etching cracks" in rolling bearings in Vestas wind turbines, in: Conference for Wind Power Drives 2021: Conference Proceedings, 9-11 March 2021, Aachen, Germany, 2021.

Johansen, S. S. and Nejad, A. R.: On digital twin condition monitoring approach for drivetrains in marine applications, in: ASME 2019 38th International Conference on Ocean, Offshore and Arctic Engineering, American Society of Mechanical Engineers Digital Collection, 2019.

Johnson, K. L.: Contact mechanics, Cambridge university press, 90-104 pp., ISBN 052134796 3, 1987.

Kahn-Jetter and, Z. L. and Wright, S.: Finite element analysis of an involute spline, J. Mech. Des., 122, 239-244, 2000.

Kazachkov, Y., Feltes, J. W., and Zavadil, R.: Modeling wind farms for power system stability studies, in: 2003 IEEE Power Engineering Society General Meeting (IEEE Cat. No. 03CH37491), vol. 3, pp. 1526-1533, IEEE, 2003.
Kim, K., Parthasarathy, G., Uluyol, O., Foslien, W., Sheng, S., and Fleming, P.: Use of SCADA data for failure detection in wind turbines, Tech. rep., National Renew. Energ. Lab.(NREL), Golden, CO (United States), 2011.

Kirsch, J. and Kyling, H.: Optimized cast components in the drive train of wind turbines and inner ring creep in the main bearing seat, Forsch. Ingenieurwesen, 85, 199-210, 2021.

Kirschneck, M., Rixen, D. J., Polinder, H., and van Ostayen, R. A.: Electromagnetomechanical coupled vibration analysis of a direct-drive off-shore wind turbine generator, J. Comput. Nonlin. Dyn., 10, 041011, https://doi.org/10.1115/1.4027837, 2015.

Koukoura, S., Carroll, J., and McDonald, A.: A Diagnostic Framework for Wind Turbine Gearboxes Using Machine Learning, in: Annual Conference of the PHM Society, 21-26 September 2019, Scottsdale, Arizona, USA, vol. 11, 2019.

Kowal, D., Sergeant, P., Dupré, L., and Vandenbossche, L.: The effect of the electrical steel properties on the temperature distribution in direct-drive PM synchronous generators for $5 \mathrm{MW}$ wind turbines, IEEE T. Magn., 49, 5371-5377, 2013.

Kuang, J. and Yang, Y.: An estimate of mesh stiffness and load sharing ratio of a spur gear pair, Advancing power transmission into the 21 st century, pp. 1-9, https://doi.org/10.1115/DETC1992$0001,1992$.

Kusiak, A. and Li, W.: The prediction and diagnosis of wind turbine faults, Renew. Energ., 36, 16-23, 2011.

Kusiak, A. and Zhang, Z.: Analysis of wind turbine vibrations based on SCADA data, J. Sol. Energ. Eng., 132, 031008, https://doi.org/10.1115/1.4001461, 2010.

Kusiak, A., Zheng, H., and Song, Z.: Models for monitoring wind farm power, Renew. Energ., 34, 583-590, 2009.

Larumbe, L. B., Qin, Z., and Bauer, P.: Introduction to the analysis of harmonics and resonances in large offshore wind power plants, in: 2018 IEEE 18th International Power Electronics and Motion Control Conference (PEMC), 26-30 August 2018, Budapest, Hungary, pp. 393-400, IEEE, 2018.

Larumbe, L. B., Qin, Z., and Bauer, P.: Output impedance modelling and sensitivity study of grid-feeding inverters with dual current control, in: IECON 2019-45th Annual Conference of the IEEE Industrial Electronics Society, 14-17 October 2019, Lisbon, Portugal, vol. 1, pp. 4007-4012, IEEE, 2019.

Larumbe, L. B., Qin, Z., Wang, L., and Bauer, P.: Impedance Modelling for Three-Phase Inverters with Double Synchronous Reference Frame Current Controller in the Presence of Imbalance, IEEE T. Power Electron., 37, 1461-1475, https://doi.org/10.1109/TPEL.2021.3107045, 2021.

Leclère, Q., André, H., and Antoni, J.: A multi-order probabilistic approach for Instantaneous Angular Speed tracking debriefing of the CMMNO14 diagnosis contest, Mech. Syst. Signal Pr., 81, 375-386, 2016.

Li, H., Hu, Y., Yang, C., Chen, Z., Ji, H., and Zhao, B.: An improved fuzzy synthetic condition assessment of a wind turbine generator system, Int. J. Elec. Power, 45, 468-476, 2013.

Li, J., Lei, X., Li, H., and Ran, L.: Normal behavior models for the condition assessment of wind turbine generator systems, Elect. Pow. Compo. Sys., 42, 1201-1212, 2014.

Li, S. and Kahraman, A.: A tribo-dynamic model of a spur gear pair, J. Sound Vib., 332, 4963-4978, 2013. 
Lim, T. C. and Singh, R.: Vibration transmission through rolling element bearings, part I: bearing stiffness formulation, J. Sound Vib., 139, 179-199, 1990.

Loriemi, A., Jacobs, G., Reisch, S., Bosse, D., and Schröder, T.: Experimental and simulation-based analysis of asymmetrical spherical roller bearings as main bearings for wind turbines, Forsch. Ingenieurwesen, 85, 189-197, https://doi.org/10.1007/s10010021-00462-1, 2021.

Lu, B., Li, Y., Wu, X., and Yang, Z.: A review of recent advances in wind turbine condition monitoring and fault diagnosis, in: Power Electronics and Machines in Wind Applications, PEMWA 2009, IEEE, pp. 1-7, IEEE, 2009.

Lydia, M., Kumar, S. S., Selvakumar, A. I., and Kumar, G. E. P.: A comprehensive review on wind turbine power curve modeling techniques, Renew. Sustain. Energ. Rev., 30, 452-460, 2014.

Manobel, B., Sehnke, F., Lazzús, J. A., Salfate, I., Felder, M., and Montecinos, S.: Wind turbine power curve modeling based on Gaussian Processes and Artificial Neural Networks, Renew. Energ., 125, 1015-1020, https://doi.org/10.1016/J.RENENE.2018.02.081, 2018.

Marrant, B., Vanhollebeke, F., and Peeters, J.: Comparison of multibody simulations and measurements of wind turbine gearboxes at Hansen's 13 MW test facility, in: European Wind Energy Conference and Exhibition (EWEC), 20-23 April 2010, Warsaw, Poland, 2010.

McDonald, A. and Bhuiyan, N. A.: On the optimization of generators for offshore direct drive wind turbines, IEEE T. Energy Conver., 32, 348-358, 2016.

McDonald, A. and Jimmy, G.: Parallel wind turbine powertrains and their design for high availability, IEEE T. Sustain. Energ., 8, 880890, 2016.

Mehlan, F. C., Nejad, A. R., and Gao, Z.: Estimation of wind turbine gearbox loads for online fatigue monitoring using inverse methods, in: Proceedings of the ASME 2021 40th International Conference on Ocean, Offshore and Arctic Engineering OMAE 2021, ASME OMAE2021: Virtual Conference: 21-30 June 2021, pp. OMAE2021-62181, ASME, 2021.

Moghadam, F. K. and Nejad, A. R.: Evaluation of PMSG-based drivetrain technologies for 10-MW floating offshore wind turbines: Pros and cons in a life cycle perspective, Wind Energy, 23, 1542-1563, 2020.

Moghadam, F. K. and Nejad, A. R.: Theoretical and experimental study of wind turbine drivetrain fault diagnosis by using torsional vibrations and modal estimation, J. Sound Vib., 509, 116223, https://doi.org/10.1016/j.jsv.2021.116223, 2021.

Moghadam, F. K. and Nejad, A. R.: Online condition monitoring of floating wind turbines drivetrain by means of digital twin, Mech. Syst. Signal Pr., 162, 108087, https://doi.org/10.1016/j.ymssp.2021.108087, 2022.

Moghadam, F. K., Rebouças, G. F. D. S., and Nejad, A. R.: Digital twin modeling for predictive maintenance of gearboxes in floating offshore wind turbine drivetrains, Forsch. Ingenieurwesen, 85, 273-286, 2021.

Moore, S.: U.S. Seeks Superconducting Offshore Wind Generators, https://spectrum.iee.org/energywise/green-tech/wind/ us-seeks-superconducting-offshore-wind-generators (last access: 12 September 2021), 2020.

Morales-Espejel, G. and Gabelli, A.: A major step forward in life modeling, Power Transmission Engineering, 11, 36-40, 2017.
Nejad, A. R. and Torsvik, J.: Drivetrains on floating offshore wind turbines: lessons learned over the last 10 years, Forsch. Ingenieurwesen, 85, 335-343, 2021.

Nejad, A. R., Gao, Z., and Moan, T.: On long-term fatigue damage and reliability analysis of gears under wind loads in offshore wind turbine drivetrains, Int. J. Fatigue, 61, 116-128, 2014a.

Nejad, A. R., Odgaard, P. F., Gao, Z., and Moan, T.: A prognostic method for fault detection in wind turbine drivetrains, Eng. Fail. Anal., 42, 324-336, 2014b.

Nejad, A. R., Bachynski, E. E., Kvittem, M. I., Luan, C., Gao, Z., and Moan, T.: Stochastic dynamic load effect and fatigue damage analysis of drivetrains in land-based and TLP, spar and semisubmersible floating wind turbines, Mar. Struct., 42, 137-153, 2015.

Nejad, A. R., Odgaard, P. F., and Moan, T.: Conceptual study of a gearbox fault detection method applied on a 5-MW spar-type floating wind turbine, Wind Energy, 21, 1064-1075, 2018.

Nejad, A. R., Bachynski, E. E., and Moan, T.: Effect of axial acceleration on drivetrain responses in a spar-type floating wind turbine, J. Offshore Mech. Arct., 141, 031901, https://doi.org/10.1115/1.4041996, 2019.

Nordmark, D. and Boyeye, J.: Service Optimization of Wind Turbine Drivetrains through Digital Solutions, in: Conference for Wind Power Drives: Conference Proceedings, 9-11 March 2021, Aachen, Germany, 2021.

Palermo, A., Mundo, D., Hadjit, R., and Desmet, W.: Multibody element for spur and helical gear meshing based on detailed threedimensional contact calculations, Mech. Mach. Theory, 62, 1330, 2013.

Pandit, R. and Infield, D.: Gaussian Process Operational Curves for Wind Turbine Condition Monitoring, Energies, 11, 1631, https://doi.org/10.3390/en11071631, 2018a.

Pandit, R. K. and Infield, D.: SCADA-based wind turbine anomaly detection using Gaussian process models for wind turbine condition monitoring purposes, IET Renewable Power Generation, 12, 1249-1255, 2018b.

Pandit, R. K., Infield, D., and Carroll, J.: Incorporating air density into a Gaussian process wind turbine power curve model for improving fitting accuracy, Wind Energy, 22, 302-315, 2019.

Peeters, C., Guillaume, P., and Helsen, J.: Vibration-based bearing fault detection for operations and maintenance cost reduction in wind energy, Renew. Energ., 116, 74-87, 2018.

Peeters, C., Leclere, Q., Antoni, J., Lindahl, P., Donnal, J., Leeb, S., and Helsen, J.: Review and comparison of tacholess instantaneous speed estimation methods on experimental vibration data, Mech. Syst. Signal Pr., 129, 407-436, 2019.

Polikarpova, M.: Liquid cooling solutions for rotating permanent magnet synchronous machines, $\mathrm{PhD}$ thesis at Lappeenranta University of Technology, Lappeenranta, Finland, https://lutpub.lut.fi/bitstream/handle/10024/101756/Thesis_ MariiaPolikarpova_A4.pdf?sequence=2 (last access: 25 September 2021), ISBN 978-952-265-672-8, 2014.

Polinder, H., Van der Pijl, F. F., De Vilder, G.-J., and Tavner, P. J.: Comparison of direct-drive and geared generator concepts for wind turbines, IEEE T. Energ. Convers., 21, 725-733, 2006.

Polinder, H., Ferreira, J., Jensen, B., Abrahamsen, A., Atallah, K., and McMahon, R.: Trends in Wind Turbine Generator Systems, IEEE J. Em. Sel. Top. P., 1, 174-185, https://doi.org/10.1109/JESTPE.2013.2280428, 2013. 
Qiao, W. and Qu, L.: Prognostic condition monitoring for wind turbine drivetrains via generator current analysis, Chinese Journal of Electrical Engineering, 4, 80-89, https://doi.org/10.23919/CJEE.2018.8471293, 2018.

Qin, Z., Liserre, M., Blaabjerg, F., and Wang, H.: Energy storage system by means of improved thermal performance of a $3 \mathrm{mw}$ grid side wind power converter, in: IECON 2013-39th Annual Conference of the IEEE Industrial Electronics Society, pp. 736742, IEEE, 2013.

Qin, Z., Blaabjerg, F., and Loh, P. C.: A rotating speed controller design method for power leveling by means of inertia energy in wind power systems, IEEE T. Energy Conver., 30, 1052-1060, 2015a.

Qin, Z., Wang, H., Blaabjerg, F., and Loh, P. C.: The feasibility study on thermal loading control of wind power converters with a flexible switching frequency, in: 2015 IEEE Energy Conversion Congress and Exposition (ECCE), pp. 485-491, IEEE, 2015b.

Qiu, Y., Feng, Y., Tavner, P., Richardson, P., Erdos, G., and Chen, B.: Wind turbine SCADA alarm analysis for improving reliability, Wind Energy, 15, 951-966, 2012.

Rai, A. and Upadhyay, S.: A review on signal processing techniques utilized in the fault diagnosis of rolling element bearings, Tribol. Int., 96, 289-306, 2016.

Randall, R. B.: Vibration-based condition monitoring: industrial, aerospace and automotive applications, John Wiley \& Sons, https://doi.org/10.1002/9780470977668, 2011.

Rassõlkin, A., Kallaste, A., Orlova, S., Gevorkov, L., Vaimann, T., and Belahcen, A.: Re-use and recycling of different electrical machines, Latvian J. Phys. Tech. Sci., 55, 13-23, 2018.

Reisch, S.: Elastic interaction of the gearbox in powertrain concepts with increased integration level, in: Conference for Wind Power Drives 2021: Conference Proceedings, 9-11 March 2021, Aachen, Germany, 2021.

Ren, Z., Verma, A. S., Li, Y., Teuwen, J. J., and Jiang, Z.: Offshore wind turbine operations and maintenance: A stateof-the-art review, Renew. Sustain. Energ. Rev., 144, 110886, https://doi.org/10.1016/J.RSER.2021.110886, 2021.

Renew. Energ. Agency, I.: RENEWABLE ENERGY TECHNOLOGIES: COST ANALYSIS SERIES Volume 1: Power Sector Acknowledgement, https://www.irena.org/Publications (last access: 20 September 2021), 2012.

Röckmann, C., Lagerveld, S., and Stavenuiter, J.: Operation and Maintenance Costs of Offshore Wind Farms and Potential Multi-use Platforms in the Dutch North Sea, in: Aquaculture Perspective of Multi-Use Sites in the Open Ocean, edited by: Buck, B. and Langan, R., Springer, Cham., 97-113, https://doi.org/10.1007/978-3-319-51159-7_4, 2017.

Rolink, A., Schröder, T., Jacobs, G., Bosse, D., Hölzl, J., and Bergmann, P.: Feasibility study for the use of hydrodynamic plain bearings with balancing support characteristics as main bearing in wind turbines, in: Journal of Physics: Conference Series, TORQUE2020, 28 September-2 October 2020, online, vol. 1618, p. 052002, IOP Publishing, 2020.

Rolink, A., Jacobs, G., Schröder, T., Keller, D., Jakobs, T., Bosse, D., Lang, J., and Knoll, G.: Methodology for the systematic design of conical plain bearings for use as main bearings in wind turbines, Forsch. Ingenieurwesen, 85, 629-637, https://doi.org/10.1007/s10010-021-00452-3, 2021.
Roscher, B., Werkmeister, A., Jacobs, G., and Schelenz, R.: Modelling of Wind Turbine Loads nearby a Wind Farm, in: Journal of Physics: Conference Series, vol. 854, p. 012038, IOP Publishing, Wake Conference 2017, 30 May-1 June 2017, Visby, Sweden, 2017.

Sartori, L., Bellini, F., Croce, A., and Bottasso, C.: Preliminary design and optimization of a 20MW reference wind turbine, in: Journal of Physics: Conference Series, vol. 1037, p. 042003, IOP Publishing, The Science of Making Torque from Wind (TORQUE 2018), 20-22 June 2018, Milan, Italy, 2018.

Sawalhi, N. and Randall, R. B.: The application of spectral kurtosis to bearing diagnostics, in: Proceedings of ACOUSTICS, Proceedings of ACOUSTICS 2004, 3-5 November 2004, Gold Coast, Australia, pp. 393-398, 2004.

Schlechtingen, M., Santos, I. F., and Achiche, S.: Wind turbine condition monitoring based on SCADA data using normal behavior models. Part 1: System description, Appl. Soft Comput., 13, 259270, 2013.

Sethuraman, L., Venugopal, V., Zavvos, A., and Mueller, M.: Structural integrity of a direct-drive generator for a floating wind turbine, Renew. Energ., 63, 597-616, 2014.

Sharma, V. and Parey, A.: A review of gear fault diagnosis using various condition indicators, Procedia Eng., 144, 253-263, 2016.

Sheng, S.: Wind turbine gearbox condition monitoring round robin study-vibration analysis, Tech. rep., National Renew. Energ. Lab. (NREL), Golden, CO (United States), 2012.

Shipurkar, U., Ma, K., Polinder, H., Blaabjerg, F., and Ferreira, J. A.: A review of failure mechanisms in wind turbine generator systems, in: 2015 17th European Conference on Power Electronics and Applications (EPE'15 ECCEEurope), 8-10 September 2015, Geneva, Switzerland, pp. 1-10, https://doi.org/10.1109/EPE.2015.7311669, 2015.

Shipurkar, U., Polinder, H., and Ferreira, J. A.: A review of methods to increase the availability of wind turbine generator systems, CPSS T. Pow. Electron. Appl., 1, 66-82, https://doi.org/10.24295/CPSSTPEA.2016.00007, 2016.

Shrestha, G., Polinder, H., Bang, D., and Ferreira, J. A.: Structural Flexibility: A Solution for Weight Reduction of Large DirectDrive Wind-Turbine Generators, IEEE T. Energ. Con., 25, 732740, 2010.

Siemens: Wind Generators, https://new.siemens.com/global/en/ markets/wind/equipment/energy-generation/windgenerators. html (last access: 21 September 2021), 2020.

Sieros, G., Chaviaropoulos, P., Sørensen, J. D., Bulder, B. H., and Jamieson, P.: Upscaling wind turbines: theoretical and practical aspects and their impact on the cost of energy: Upscaling wind turbines: theoretical and practical aspects, Wind Energy, 15, 317, https://doi.org/10.1002/we.527, 2012.

Silva, P., Giuffrida, A., Fergnani, N., Macchi, E., Cantù, M., Suffredini, R., Schiavetti, M., and Gigliucci, G.: Performance prediction of a multi-MW wind turbine adopting an advanced hydrostatic transmission, Energy, 64, 450-461, 2014.

SKF: Wind Generators, https://www.skf.com/mena/services/ recondoil (last access: 21 September 2021), 2021.

Slootweg, J., De Haan, S., Polinder, H., and Kling, W.: General model for representing variable speed wind turbines in power system dynamics simulations, IEEE T. Pow. Syst., 18, 144-151, 2003. 
Sopanen, J., Ruuskanen, V., Nerg, J., and Pyrhonen, J.: Dynamic torque analysis of a wind turbine drive train including a directdriven permanent-magnet generator, IEEE T. Ind. Electron., 58, 3859-3867, 2010.

Spinato, F., Tavner, P. J., Van Bussel, G. J., and Koutoulakos, E.: Reliability of wind turbine subassemblies, IET Renew. Pow. Generation, 3, 387-401, 2009.

Steffen, B., Beuse, M., Tautorat, P., and Schmidt, T. S.: Experience Curves for Operations and Maintenance Costs of Renew. Energ. Technologies, Joule, 4, 359-375, https://doi.org/10.1016/J.JOULE.2019.11.012, 2020.

Stehouwer, E. and van Zinderen, G. J.: Conceptual nacelle designs of 10-20 MW wind turbines, Tech. Rep. Deliverable D3.41, 2016.

Stetco, A., Dinmohammadi, F., Zhao, X., Robu, V., Flynn, D., Barnes, M., Keane, J., and Nenadic, G.: Machine learning methods for wind turbine condition monitoring: A review, Renew. Energ., 133, 620-635, 2019.

Struggl, S., Berbyuk, V., and Johansson, H.: Review on wind turbines with focus on drive train system dynamics, Wind Energy, 18, 567-590, 2015.

Sun, P., Li, J., Wang, C., and Lei, X.: A generalized model for wind turbine anomaly identification based on SCADA data, Appl. Energ., 168, 550-567, 2016.

Tartt, K., Nejad, A. R., Amiri, A. K., and McDonald, A.: On lifetime extension of wind turbine drivetrains, in: Proceedings of the ASME 2021 40th International Conference on Ocean, Offshore and Arctic Engineering OMAE 2021, ASME OMAE2021: Virtual Conference: 21-30 June 2021, pp. OMAE2021-62 516, ASME, 2021.

Tautz-Weinert, J. and Watson, S. J.: Using SCADA data for wind turbine condition monitoring-a review, IET Renew. Pow. Gen., 11, 382-394, 2016.

Tchakoua, P., Wamkeue, R., Ouhrouche, M., Slaoui-Hasnaoui, F., Tameghe, T. A., and Ekemb, G.: Wind turbine condition monitoring: State-of-the-art review, new trends, and future challenges, Energies, 7, 2595-2630, 2014.

Topham, E. and McMillan, D.: Sustainable decommissioning of an offshore wind farm, Renew. Energ., 102, 470-480, https://doi.org/10.1016/j.renene.2016.10.066, 2017.

Topham, E., Gonzalez, E., McMillan, D., and João, E.: Challenges of decommissioning offshore wind farms: overview of the European experience, in: Journal of Physics: Conference Series, vol. 1222, p. 012035, IOP Publishing, WindEurope Conference and Exhibition 2019, 2-4 April 2019, Bilbao, Spain, 2019a.

Topham, E., McMillan, D., Bradley, S., and Hart, E.: Recycling offshore wind farms at decommissioning stage, Energ. Pol., 129, 698-709, 2019b.

Torsvik, J., Nejad, A. R., and Pedersen, E.: Main bearings in large offshore wind turbines: development trends, design and analysis requirements, in: Journal of Physics: Conference Series, vol. 1037, p. 042020, IOP Publishing, The Science of Making Torque from Wind (TORQUE 2018), 20-22 June 2018, Milan, Italy, 2018.

Torsvik, J., Nejad, A. R., and Pedersen, E.: Experimental field study of floater motion effects on a main bearing in a fullscale spar floating wind turbine, Mar. Struct., 79, 103059, https://doi.org/10.1016/j.marstruc.2021.103059, 2021.
Tracht, K., Goch, G., Schuh, P., Sorg, M., and Westerkamp, J. F.: Failure probability prediction based on condition monitoring data of wind energy systems for spare parts supply, CIRP Annals, 62, 127-130, 2013.

Trevisan, A. S., El-Deib, A. A., Gagnon, R., Mahseredjian, J., and Fecteau, M.: Field validated generic EMT-type model of a full converter wind turbine based on a gearless externally excited synchronous generator, IEEE T. Pow. Delivery, 33, 2284-2293, 2018.

Turnbull, A., Carroll, J., McDonald, A., and Koukoura, S.: Prediction of wind turbine generator failure using two-stage clusterclassification methodology, Wind Energy, 22, 1593-1602, 2019.

Ugalde-Loo, C. E., Ekanayake, J. B., and Jenkins, N.: State-space modeling of wind turbine generators for power system studies, IEEE T. Indust. Appl., 49, 223-232, 2012.

Ullah, N. R., Larsson, A., Petersson, A., and Karlsson, D.: Detailed modeling for large scale wind power installations-a real project case study, in: 2008 Third International Conference on Electric Utility Deregulation and Restructuring and Power Technologies, pp. 46-56, IEEE, 2008.

Vaes, D., Clement, P., and Lindstedt, U.: Roller bearings for the next generation of wind gearboxes, in: Conference for Wind Power Drives 2021: Conference Proceedings, 9-11 March 2021, Aachen, Germany, 2021.

van Binsbergen, D. W., Wang, S., and Nejad, A. R.: Effects of induction and wake steering control on power and drivetrain responses for $10 \mathrm{MW}$ floating wind turbines in a wind farm, Journal of Physics: Conference Series, 1618, 022044, TORQUE2020, 28 September-2 October 2020, online, 2020.

van Binsbergen, D. W., Nejad, A. R., and Helsen, J.: Dynamic model development of wind turbine drivetrains by using sensor measurments, in: Proceedings of the ASME 2021 40th International Conference on Ocean, Offshore and Arctic Engineering OMAE 2021, 21-30 June 2021, pp. OMAE2021-61 939, ASME, 2021.

Vanhollebeke, F., Peeters, J., Vandepitte, D., and Desmet, W.: Using transfer path analysis to assess the influence of bearings on structural vibrations of a wind turbine gearbox, Wind Energy, 18, 797-810, 2015.

Večeř, P., Kreidl, M., and Šmíd, R.: Condition indicators for gearbox condition monitoring systems, Acta Polytechnica, 45, 3543, https://doi.org/10.14311/782, 2005.

Veers, P., Dykes, K., Lantz, E., Barth, S., Bottasso, C. L., Carlson, O., Clifton, A., Green, J., Green, P., Holttinen, H., Laird, D., Lehtomäki, V., Lundquist, J. K., Manwell, J., Marquis, M., Meneveau, C., Moriarty, P., Munduate, X., Muskulus, M., Naughton, J., Pao, L., Paquette, J., Peinke, J., Robertson, A., Rodrigo, J. S., Sempreviva, A. M., Smith, J. C., Tuohy, A., and Wiser, R.: Grand challenges in the science of wind energy, Science, 366, 6464, https://doi.org/10.1126/science.auu2027, 2019.

Veers, P., Sethuraman, L., and Keller, J.: Wind-power generator technology research aims to meet global-wind power ambitions, Joule, 4, 1861-1863, 2020.

Verstraeten, T., Marulanda, F. G., Peeters, C., Daems, P.-J., Nowé, A., and Helsen, J.: Edge computing for advanced vibration signal processing, in: Surveillance, Vishno and AVE conferences, 8-10 July 2019, Lyon, France, 2019. 
Vijayakar, S.: A combined surface integral and finite element solution for a three-dimensional contact problem, Int. J. Numer. Meth. Eng., 31, 525-545, 1991.

Vree, D., Larumbe, L. B., Qin, Z., Bauer, P., and Ummels, B.: Impact of WTG converter impedance model on harmonic amplification factor of the Dutch $110 \mathrm{kV}$ transmission network using a 383MW wind farm case study, in: Cigre 2020 E-session, Cigré, 2020.

Wächter, M., Lind, P., Hernandez, I. H., Rinn, P., Milan, P., Stoevesandt, B., and Peinke, J.: Efficient load and power monitoring by stochastic methods, EWEA 2015 Annual Event, 17-20 November 2015, Paris, France, 2015.

Wang, Q., Zhao, B., Fu, Y., Kong, X., and Ma, H.: An improved time-varying mesh stiffness model for helical gear pairs considering axial mesh force component, Mech. Syst. Signal Pr., 106, 413-429, 2018.

Wang, S., Nejad, A. R., Bachynski, E. E., and Moan, T.: Effects of bedplate flexibility on drivetrain dynamics: Case study of a $10 \mathrm{MW}$ spar type floating wind turbine, Renew. Energ., 161, 808-824, 2020.

Watson, S., Kennedy, I., and Gray, C.: The use of physics of failure modelling in wind turbine condition monitoring, in: EWEA Annual Conf, vol. 2011, 14-17 March 2011, Brussels, Belgium, pp. 309-312, 2011.

Weber, A. and Hansen, A.: Focus areas in Vestas powertrain, in: Conference for Wind Power Drives 2021: Conference Proceedings, 9-11 March 2021, Aachen, Germany, 2021.

Weber, C. and Banaschek, K.: The deformation of loaded gears and the effect on their load-carrying capacity, British Scientific and Industrial Research, Report No. 3, 111 pp., 1949.

Wilkinson, M., Darnell, B., Van Delft, T., and Harman, K.: Comparison of methods for wind turbine condition monitoring with SCADA data, IET Renew. Pow. Gen., 8, 390-397, 2014.

Wind Europe: Offshore Wind in Europe, Key trends and statistics 2019, https://windeurope. org/wp-content/uploads/files/about-wind/statistics/

WindEurope-Annual-Offshore-Statistics-2019.pdf, last access: 14 August 2020.

Windpower, Z.: Modular Gearbox Platform Designs, https:// www.zf.com/products/en/wind/shift/shift.html (last access: 21 September 2021), 2021.

Wiser, R., Bolinger, M., and Lantz, E.: Assessing Wind Power Operating Costs in the United States: Results from a Survey of Wind Industry Experts, Renew. Energ. Focus, 30, 46-57, 2019.
Wu, Z. and Huang, N. E.: Ensemble empirical mode decomposition: a noise-assisted data analysis method, Adv. Adapt. Data Anal., 1, 1-41, 2009.

Yang, W., Court, R., and Jiang, J.: Wind turbine condition monitoring by the approach of SCADA data analysis, Renew. Energ., 53, 365-376, 2013.

Yang, W., Tavner, P. J., Crabtree, C. J., Feng, Y., and Qiu, Y.: Wind turbine condition monitoring: technical and commercial challenges, Wind Energy, 17, 673-693, 2014.

Yaramasu, V., Wu, B., Sen, P. C., Kouro, S., and Narimani, M.: High-power wind energy conversion systems: State-of-the-art and emerging technologies, Proceedings of the IEEE, 103, 740 788, https://doi.org/10.1109/JPROC.2014.2378692, 2015.

Zaher, A., McArthur, S., Infield, D., and Patel, Y.: Online wind turbine fault detection through automated SCADA data analysis, Wind Energy: An International Journal for Progress and Applications in Wind Power Conversion Technology, 12, 574-593, 2009.

Zakrajsek, J. J., Townsend, D. P., and Decker, H. J.: An analysis of gear fault detection methods as applied to pitting fatigue failure data, Tech. rep., National Aeronautics and Space Administration Cleveland OH Lewis Research Center, 1993.

Zeichfüß1, R., Jöckel, A., Deicke, M., Daners, D., and Fox, C.: Integrated 3-stage planetary gearbox with oil-cooled generator, in: Conference for Wind Power Drives 2021: Conference Proceedings, 9-11 March 2021, Aachen, Germany, 2021.

Zhou, D., Blaabjerg, F., Lau, M., and Tonnes, M.: Thermal profile analysis of doubly-fed induction generator based wind power converter with air and liquid cooling methods, in: 2013 15th European Conference on Power Electronics and Applications (EPE), 2-6 September 2013, Lille, France, pp. 1-10, IEEE, 2013.

Zhou, J., Guo, P., and Wang, X. R.: Modeling of wind turbine power curve based on Gaussian process, Proceedings - International Conference on Machine Learning and Cybernetics, 1, 71-76, https://doi.org/10.1109/ICMLC.2014.7009094, 2014.

Zhu, J., Nostrand, T., Spiegel, C., and Morton, B.: Survey of condition indicators for condition monitoring systems, in: Annu. Conf. Progn. Heal. Manag. Soc, vol. 5, pp. 1-13, 2014.

Ziegler, L., Gonzalez, E., Rubert, T., Smolka, U., and Melero, J. J.: Lifetime extension of onshore wind turbines: A review covering Germany, Spain, Denmark, and the UK, Renew. Sustain. Energ. Rev., 82, 1261-1271, https://doi.org/10.1016/j.rser.2017.09.100, 2018. 